\title{
Intelligent Backpropagation Networks with Bayesian Regularization for Mathematical Models of Environmental Economic Systems
}

\author{
Adiqa Kausar Kiani ${ }^{1}{ }^{\complement}$, Wasim Ullah Khan ${ }^{2}$, Muhammad Asif Zahoor Raja ${ }^{1,3} \mathbb{D}$, Yigang He ${ }^{2, *}$, Zulqurnain Sabir ${ }^{4}$ \\ and Muhammad Shoaib ${ }^{5}$ (D) \\ 1 Future Technology Research Center, National Yunlin University of Science and Technology, \\ 123 University Road, Section 3, Douliou, Yunlin 64002, Taiwan; adiqa@yuntech.edu.tw (A.K.K.); \\ rajamaz@yuntech.edu.tw (M.A.Z.R.) \\ 2 A School of Electrical Engineering and Automation, Wuhan University, East Lake South Road No. 8, \\ Wuhan 430072, China; kwasim814@whu.edu.cn \\ 3 Department of Electrical and Computer Engineering, COMSATS University Islamabad, Attock Campus, \\ Attock 43600, Pakistan \\ 4 Department of Mathematics and Statistics, Hazara University, Mansehra 21120, Pakistan; \\ zulqurnain_maths@hu.edu.pk \\ 5 Department of Mathematics, COMSATS University Islamabad, Attock Campus, Attock 43600, Pakistan; \\ dr.shoaib@cuiatk.edu.pk \\ * Correspondence: yghe1221@whu.edu.cn
}

check for updates

Citation: Kiani, A.K.; Khan, W.U.; Raja, M.A.Z.; He, Y.; Sabir, Z.; Shoaib, M. Intelligent Backpropagation Networks with Bayesian

Regularization for Mathematical Models of Environmental Economic Systems. Sustainability 2021, 13, 9537. https://doi.org/10.3390/ su13179537

Academic Editor: Magdalena Tutak

Received: 14 May 2021

Accepted: 18 June 2021

Published: 25 August 2021

Publisher's Note: MDPI stays neutral with regard to jurisdictional claims in published maps and institutional affiliations.

Copyright: (c) 2021 by the authors. Licensee MDPI, Basel, Switzerland. This article is an open access article distributed under the terms and conditions of the Creative Commons Attribution (CC BY) license (https:// creativecommons.org/licenses/by/ $4.0 /)$
Abstract: The research community of environmental economics has had a growing interest for the exploration of artificial intelligence (AI)-based systems to provide enriched efficiencies and strengthened human knacks in daily live maneuvers, business stratagems, and society evolution. In this investigation, AI-based intelligent backpropagation networks of Bayesian regularization (IBNsBR) were exploited for the numerical treatment of mathematical models representing environmental economic systems (EESs). The governing relations of EESs were presented in the form of differential models representing their fundamental compartments or indicators for economic and environmental parameters. The reference datasets of EESs were assembled using the Adams numerical solver for different EES scenarios and were used as targets of IBNs-BR to find the approximate solutions. Comparative studies based on convergence curves on the mean square error (MSE) and absolute deviation from the reference results were used to verify the correctness of IBNs-BR for solving EESs, i.e., MSE of around $10^{-9}$ to $10^{-10}$ and absolute error close to $10^{-5}$ to $10^{-7}$. The endorsement of results was further validated through performance evaluation by means of error histogram analysis, the regression index, and the mean squared deviation-based figure of merit for each EES scenario.

Keywords: environmental economic system; backpropagation networks; Bayesian regularization; Adams numerical solver; regression index

\section{Introduction}

Differential equations-based modeling is extensively use for measuring the behavior of complex systems representing different applications of applied sciences, engineering, and technologies. The role of mathematical modeling in environments such as economic and management studies exploiting supply chain dynamics has been growing in interest in the research community in recent years due to the wide utilization in social, industrial, and commercial organizations; starting from the processing from the raw material to the final products, as well as their effective distribution or delivery to clients [1-5]. Conceptual or theoretical investigations are a mandatory phase in order to enhance the operational and financial benefits for the involved companies, optimizing the total cost with reasonable balance of the inventories [6,7]. Thus, different mathematical representations are constructed for a variety of scenarios to predict the feasible situation more accurately [8-10]. 
For example, to forecast the progress of interrelated economies, one has to consider that the economies of countries with relatively low levels of development have economical losses as the world's leading economies suffer due to the economic crisis; therefore, "predatorvictim"-type [11] mathematical models accurately represent their descriptions with the help of a liability differential system as follows [12]:

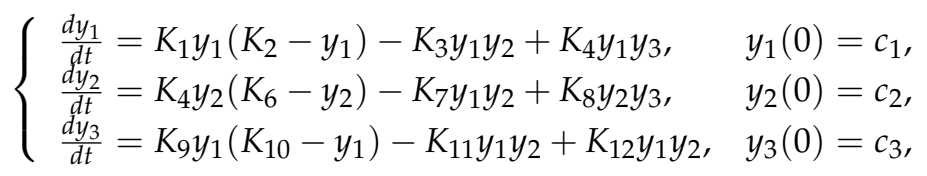

where $K_{i}$ is the $i$ th function representation of inputs, $y_{1}$ and $y_{2}$ stand for economical strong countries or regions, while $y_{3}$ is the low economic country representation with suitable conditions.

Another environmental economic model based on three class nonlinear differential equations is given as [12]:

$$
\begin{cases}\frac{d y_{1}}{d t}=K_{1} y_{1}+K_{2} y_{2}+K_{3} y_{3}, & y_{1}(0)=c_{1} \\ \frac{d y_{2}}{d t}=K_{4} y_{1}-K_{5} y_{3}, & y_{2}(0)=c_{2} \\ \frac{d y_{3}}{d t}=K_{6} y_{1}-K_{7} y_{2}+K_{8} y_{3}, & y_{3}(0)=c_{3}\end{cases}
$$

where $y_{1}$ is the population of the region or country, $y_{2}$ is the population level that represents the nonharmful characteristic of the environment due to economic activities of the masses, and $y_{3}$ is the flora level of the region.

Similarly, consider another representation of environmental economic differential systems with different settings of indicators as follows [12]:

$$
\begin{cases}\frac{d y_{1}}{d t}=K_{1} y_{1}\left(a-y_{1}\right)-K_{2} y_{2}+K_{3} y_{3}, & y_{1}(0)=c_{1} \\ \frac{d y_{2}}{d t}=K_{4} y_{1}\left(a-y_{1}\right)-K_{5}\left(b-y_{2}\right)+K_{6} y_{3}, & y_{2}(0)=c_{2} \\ \frac{d y_{3}}{d t}=K_{7} y_{1}+K_{8} y_{2}, & y_{3}(0)=c_{3}\end{cases}
$$

where $y_{1}$ is the technical diagnostics implementation cost, $y_{2}$ is the elimination cost emergencies consequences, $y_{3}$ is the industrial system efficiency, and $K_{i}$ is the $i$ th known function or constants. The existing studies available for analyzing the dynamics of EESs are based on numerical and analytical procedures of deterministic nature, while the stochastic or probabilistic procedure based on the exploitation of artificial intelligence (AI) methodologies is relatively less implemented for the analysis of the EESs, as represented in Equations (1)-(3).

Probabilistic methodologies via AI algorithms have been implemented exhaustively for a variety of linear/nonlinear systems arising in a spectrum of applications in social, economic, environment, physical, and engineering disciplines [13-17]. A few illustrations of paramount interest include ecological studies [18], acoustics [19], physics [20-24], bioinformatics [25-31], fluid dynamics [32-35], financial mathematics [36,37], and energy [38]. These motivational recent relevant and valuable reported articles inspired authors to investigate the intelligence computing paradigm for numerical treatment and analysis for EESs.

The innovative insights and contributions of the proposed stochastic computing via intelligent backpropagation networks of Bayesian regularization (IBNs-BR) $[39,40]$ are briefly listed as follows:

- A novel application of AI-based intelligent backpropagation networks via Bayesian regularization for a nonlinear environmental economic system is presented effectively.

- The reference datasets for IBNs-BR for variants of a nonlinear environmental economic system are accurately assembled by implementation of the Adams numerical solver for different scenarios and are used as targets to find the approximate solutions.

- The governing mathematical relations of the nonlinear environmental economic system in the form of different differential models representing the fundamental com- 
partments or indicators are viably solved with reasonable precision by the proposed IBNs-BR.

- The comparative studies based on convergence curves on the mean square error, error histogram analysis, and regression index are used to verify further the correctness of the IBNs-BR for each EES scenario.

The remaining sections of the paper are arranged as follows: Section 2 describes the mathematical representations of EESs for numerical experimentations. Section 3 describes the methodology adopted for solving EESs. Section 4 presents outcomes of the simulation studies of IBNs-BR. Section 5 provides a brief conclusion along with future research openings.

\section{Mathematical Representations}

In this section, the mathematical representation of the environmental economic systems provided in Equations (1)-(3) are presented for four scenarios. These four scenarios are constructed by variations in the coefficients $K_{i}$ of environmental economic indications that represent the rate or probability of linkage between variables. One of the reported scenarios of the environmental economic model [12] is given as follows:

$$
\begin{cases}\frac{d y_{1}}{d t}=0.2 y_{1}\left(5-y_{1}\right)-0.3 y_{2}+0.4 y_{3}, & y_{1}(0)=2 \\ \frac{d y_{2}}{d t}=0.2 y_{1}\left(5-y_{1}\right)-0.3 y_{2}\left(5-y_{2}\right)+0.3 y_{3}, & y_{2}(0)=4 \\ \frac{d y_{3}}{d t}=0.4 y_{1}+0.3 y_{2}, & y_{3}(0)=3\end{cases}
$$

while, to check the accuracy, robustness, and stability of the proposed IBNs-BR scheme, three different scenarios based on appropriate values of the coefficients of environmental economic models (1-3) are constructed as follows:

$$
\begin{gathered}
\begin{cases}\frac{d y_{1}}{d t}=0.2 y_{1}\left(5-y_{1}\right)-0.3 y_{2}+0.4 y_{3}, & y_{1}(0)=4, \\
\frac{d y_{2}}{d t}=0.2 y_{1}\left(5-y_{1}\right)-0.3 y_{2}\left(5-y_{2}\right)+0.3 y_{3}, & y_{2}(0)=6, \\
\frac{d y_{3}}{d t}=0.2 y_{1}-0.3 y_{2}, & y_{3}(0)=2,\end{cases} \\
\begin{cases}\frac{d y_{1}}{d t}=0.2 y_{1}\left(5-y_{1}\right)+0.3 y_{2}+0.4 y_{3}, & y_{1}(0)=2, \\
\frac{d y_{2}}{d t}=0.2 y_{1}\left(5-y_{1}\right)-0.3 y_{2}\left(5-y_{2}\right)+0.3 y_{3}, & y_{2}(0)=4 \\
\frac{d y_{3}}{d t}=0.3 y_{1}-0.4 y_{2}, & y_{3}(0)=3,\end{cases} \\
\begin{cases}\frac{d y_{1}}{d t}=0.7 y_{1}\left(5-y_{1}\right)+0.6 y_{2}+0.8 y_{3}, & y_{1}(0)=2, \\
\frac{d y_{2}}{d t}=0.7 y_{1}\left(5-y_{1}\right)+0.6 y_{2}\left(5-y_{2}\right)+0.7 y_{3}, & y_{2}(0)=7, \\
\frac{d y_{3}}{d t}=0.5 y_{1}-0.8 y_{2}, & y_{3}(0)=1,\end{cases}
\end{gathered}
$$

\section{Solution Methodology}

The stochastic soft computing platform has been extensively used by the research community for addressing different applications of paramount interest arising in a broad domain of applied science and engineering. A few examples exploiting the strength of AI methods as reliable and effective solution approaches include online learning, scheduling via multi-objective optimization [41], nonlinear Falkner-Skan systems [42], the berth scheduling problem at marine container terminals [43], the entropy generation model [44], density estimation [45], the vehicle routing problem [46], nonlinear Lane-Emden multipantograph delay differential systems [47], the identification of differences between bacterial and viral meningitis [48], the Bouc-Wen hysteresis model for piezostage actuators [49], data classification [50], and the parameter estimation of power signals [51]. All these illustrations prove the worth of heuristics and meta-heuristics methodologies.

The solution methodology for the proposed IBNs-BR to solve EESs consists of two parts: first, dataset generation for IBNs-BR by an appropriate numerical procedure; and secondly, execution of IBNs-BR with the generated data to approximate the solutions 
of EESs. The generic workflow diagram of the proposed IBNs-BR for EESs is provided in Figure 1.
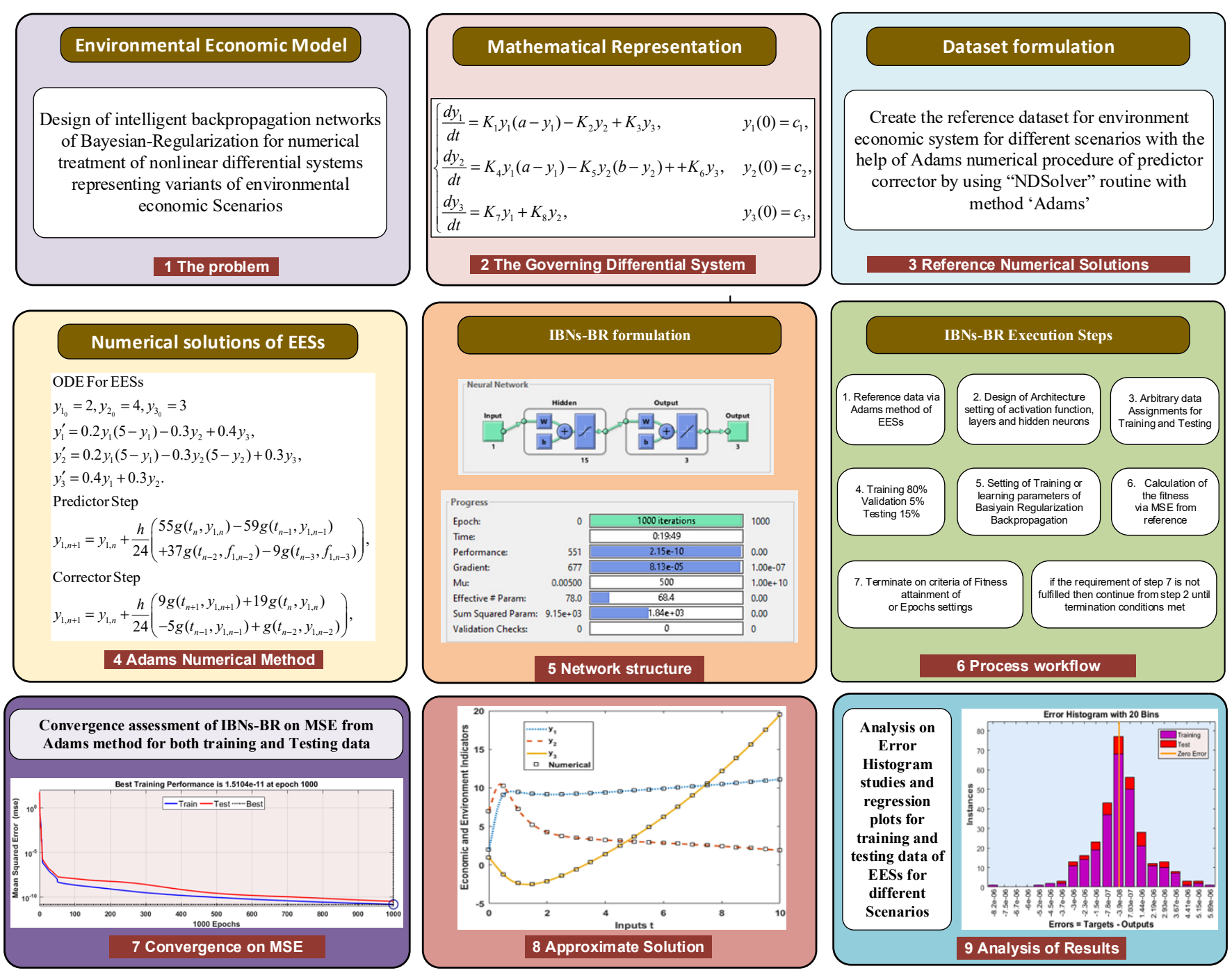

Figure 1. Process workflow of IBNs-BR for solving EESs.

\subsection{Adams Method}

The numerical procedure of the Adams predictor-corrector scheme was implemented to assemble the reference dataset for the proposed IBNs-BR to find the approximate results for EESs represented in Equations (1)-(3) and the particular scenarios provided in Equations (4)-(7). The detailed mathematical procedure for the reproduction of results with the Adams method is provided in Appendix A, while, in the said study, the Adams procedure is implemented with the auto adjustment of steps from 2 to 12 with the help of the 'NDSolve' routine for the numerical solution of differential equations [52,53], as provided in Mathematica software for solving variants of EESs.

\subsection{Intelligent Backpropagation Networks of Bayesian-Regularization}

The dataset assembled with the Adams numerical procedure was used as standard target outputs for the IBNs-BR. It was constructed with a neuron model formulation with log-sigmoid activation or a windowing kernel, as depicted in Figure 2, in the form of input, hidden, and output layers, while the all-encompassing process block flow is shown in Figure 1. The designed IBNs-BR models were implemented using the neural networks toolbox in Matlab for AI and machine learning paradigms. The weights of networks 
were trained/tuned/learned by exploitation of the backpropagation strength of Bayesian regularization procedures $[52,53]$.

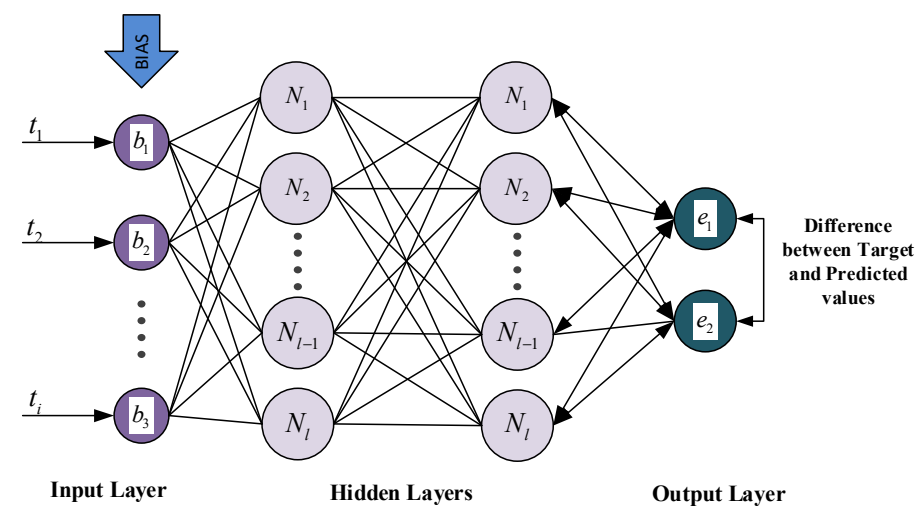

Figure 2. Schematic of input, output, and hidden layers of generic multi-layers structure of neural networks.

\section{Results with Discussion}

The numerical experimentation with detailed interpretations of the results for solving EESs as given in Equations (4)-(7) using the IBNs-BR approach is presented here.

\subsection{Dataset Formulation}

The first phase of the methodology implemented for the solution of EESs with the help of the Adams numerical procedure is illustrated in this section to create a dataset for all four variants presented in Equations (4)-(7). The system (4) for implementation of the Adams procedure is given as follows:

$$
\begin{aligned}
& y_{1_{0}}=2, y_{2_{0}}=4, y_{3_{0}}=3 \\
& y^{\prime}=\frac{d y_{1}}{d t}, y^{\prime}=\frac{d y_{2}}{d t}, y^{\prime}{ }_{3}=\frac{d y_{3}}{d t} \\
& y^{\prime}{ }_{1}=0.2 y_{1}\left(5-y_{1}\right)-0.3 y_{2}+0.4 y_{3} \\
& y^{\prime}{ }_{2}=0.2 y_{1}\left(5-y_{1}\right)-0.3 y_{2}\left(5-y_{2}\right)+0.3 y_{3} \\
& y^{\prime}{ }_{3}=0.4 y_{1}+0.3 y_{2} .
\end{aligned}
$$

Similarly, one can develop the expressions for systems in 5, 6, and 7. The dataset created all four EESs for inputs between 0 to 10 with a step size of 0.1 using the Adams solver with default parameters, i.e., accuracy goal, stoppage criteria, and relative error tolerances. The dataset based on solutions, i.e., $y_{1}, y_{2}$, and $y_{3}$, for all four EESs for 101 inputs was formulated and is presented for fewer selected inputs in Table 1, for systems in 4, 5, 6 , and 7, respectively, with 3 decimal places of accuracy, while these reference solutions

\begin{tabular}{|c|c|c|c|c|c|c|c|c|c|c|c|c|}
\hline \multirow{2}{*}{$\mathbf{t}$} & \multicolumn{3}{|c|}{ Scenario 1} & \multicolumn{3}{|c|}{ Scenario 2} & \multicolumn{3}{|c|}{ Scenario 3} & \multicolumn{3}{|c|}{ Scenario 4} \\
\hline & $y_{1}(t)$ & $y_{2}(t)$ & $y_{3}(t)$ & $y_{1}(t)$ & $y_{2}(t)$ & $y_{3}(t)$ & $y_{1}(t)$ & $y_{2}(t)$ & $y_{3}(t)$ & $y_{1}(t)$ & $y_{2}(t)$ & $y_{3}(t)$ \\
\hline 0 & 2 & 4 & 3 & 4 & 6 & 2 & 2 & 4 & 3 & 9.130 & 10.281 & -1.226 \\
\hline 1.0 & 5.385 & 5.600 & 3.022 & 6.099 & 5.786 & 1.225 & 5.156 & 4.540 & 2.342 & 9.452 & 7.236 & -2.368 \\
\hline 2.0 & 6.782 & 4.923 & 3.901 & 6.3832 & 4.405 & 0.959 & 6.271 & 3.314 & 2.496 & 9.225 & 5.253 & -2.490 \\
\hline 3.0 & 7.136 & 3.730 & 5.404 & 6.256 & 3.373 & 1.071 & 6.440 & 1.939 & 3.374 & 9.146 & 4.268 & -2.078 \\
\hline 4.0 & 7.380 & 2.877 & 7.324 & 6.169 & 2.823 & 1.392 & 6.556 & 1.073 & 4.734 & 9.164 & 3.776 & -1.388 \\
\hline
\end{tabular}
are provided in Appendix B, Tables A1-A4, for up to 15 decimal places of accuracy. The IBNs-RB were trained with reference data with higher decimal places of accuracy to avoid the rounding of error issues.

Table 1. Reference dataset for the environmental economic systems for scenarios 1 to 4 . 
Table 1. Cont.

\begin{tabular}{|c|c|c|c|c|c|c|c|c|c|c|c|c|}
\hline \multirow{2}{*}{$\mathbf{t}$} & \multicolumn{3}{|c|}{ Scenario 1} & \multicolumn{3}{|c|}{ Scenario 2} & \multicolumn{3}{|c|}{ Scenario 3} & \multicolumn{3}{|c|}{ Scenario 4} \\
\hline & $y_{1}(t)$ & $y_{2}(t)$ & $y_{3}(t)$ & $y_{1}(t)$ & $y_{2}(t)$ & $y_{3}(t)$ & $y_{1}(t)$ & $y_{2}(t)$ & $y_{3}(t)$ & $y_{1}(t)$ & $y_{2}(t)$ & $y_{3}(t)$ \\
\hline 5.0 & 7.701 & 2.309 & 9.564 & 6.175 & 2.563 & 1.822 & 6.795 & 0.576 & 6.413 & 9.233 & 3.514 & -0.542 \\
\hline 6.0 & 8.086 & 1.864 & 12.095 & 6.249 & 2.435 & 2.316 & 7.131 & 0.236 & 8.340 & 9.326 & 3.354 & 0.405 \\
\hline 7.0 & 8.507 & 1.444 & 14.917 & 6.358 & 2.351 & 2.858 & 7.516 & -0.069 & 10.503 & 9.433 & 3.239 & 1.432 \\
\hline 8.0 & 8.948 & 1.004 & 18.039 & 6.486 & 2.276 & 3.449 & 7.923 & -0.393 & 12.910 & 9.549 & 3.141 & 2.529 \\
\hline 9.0 & 9.405 & 0.526 & 21.479 & 6.624 & 2.195 & 4.089 & 8.343 & -0.753 & 15.578 & 9.670 & 3.050 & 3.693 \\
\hline 10.0 & 9.874 & 0.001 & 25.254 & 6.769 & 2.106 & 4.783 & 8.775 & -1.154 & 18.526 & 9.796 & 2.958 & 4.9246 \\
\hline
\end{tabular}

\subsection{Implementation of IBNs-BR to EESs}

The created dataset was used arbitrarily for training, $80 \%$ of 303 input grid points, and testing, i.e., 15\% of 303 input grid points, by the IBNs-BR procedure, i.e., 15 hidden neurons, log-sigmoid transfer function, and single input, output, and hidden layers, for solving EESs in Equations (4)-(7). The procedure of the IBNs-BR implemented using the 'nftool' routine in the neural network toolbox of Matlab software for all four problems of EESs and results on the basis of the mean square error (MSE), i.e., average absolute of the difference between estimated targets and original targets of reference numerical outcomes, are plotted in Figures 3-5.

Figure $3 \mathrm{a}-\mathrm{d}$ provide the convergence against epoch number for solving a set of Equations (4)-(7), by the designed IBNs-RB, respectively. The final execution parameters of IBNs-RB in terms of epochs, consume time, performance, gradient, $\mu$, effective number, and sum of squared are illustrated for EESs in (4)-(7) in Figure $4 a-d$, respectively.

The fitness plots with respect to the target outputs along with the absolute error from reference outputs are illustrated in Figure 5a-d for the four EES differential models. One may observe from Figure 3 that the performance was in close vicinity of $10^{-10}$, while the time taken by IBNs-RB was around $1000 \pm 100 \mathrm{~s}$. The testing, best, and training curves on MSE lay around $10^{-10}$ for all four systems given in Equations (4)-(7), as shown in Figure 4. The value of the gradient lay around $10^{-5}$ to $10^{-7}$, as predicted from Figure 5 . The information presented in Figure 5 shows that the maximum value of absolute error lay around $10^{-4}$ to $10^{-6}$ for solving each EES differential model by IBNs-RB.

A detailed analysis of the performance of the IBNs-RB was conducted with the help of histogram studies and regression values for each EES variant. The results of error histogram plots and regression are provided in Figures 6 and 7, respectively. One may see from subfigures of Figure 7 that the maximum instances-based error bar with values $6.72 \times 10^{-7}$, $-3.90 \times 10^{-7},-1.20 \times 10^{-5}$, and $2.59 \times 10^{-6}$ contained the desired zero error line, for EESs in Equations (4)-(7), respectively, which show the reasonable precision/accuracy of IBNs-RB. Additionally, the values of regression were consistently equal to the desired unity values for training, testing, and all datasets for all four variants of EESs solved with the IBNs-RB, as shown in Figure $7 \mathrm{a}-\mathrm{d}$. The large overfitting or consistent accuracy of the proposed ANNs-BR scheme in each sample point in training and testing, i.e., the value of regression index $R$, was very close to its optimal unity value in the case of perfect modeling. However, if the percentages of sampling data were changed drastically, i.e., $50 \%$ training and 50\% testing, the consistency accuracy in the training sample would still be achieved, i.e., value of $\mathrm{R}$ close to unity, but the overfitting observed in testing was not large, and all samplebased data plots of regression, i.e., the values of $R$, were not as close to unity. Regression plots of the exhaustive numerical experimentation with $\mathrm{R}$ close to its optimal value further endorsed the worth of the proposed IBNs-BR. Additionally, we have also critically reviewed the recent reported articles of supervised neural networks $[32,33,35,39,46]$ and found the same trend of regression plots. 
(a) Results for

IBNs-BR

convergence for

EES in Scenario 1

(b) Results for

IBNs-BR

convergence for

EES in Scenario 2

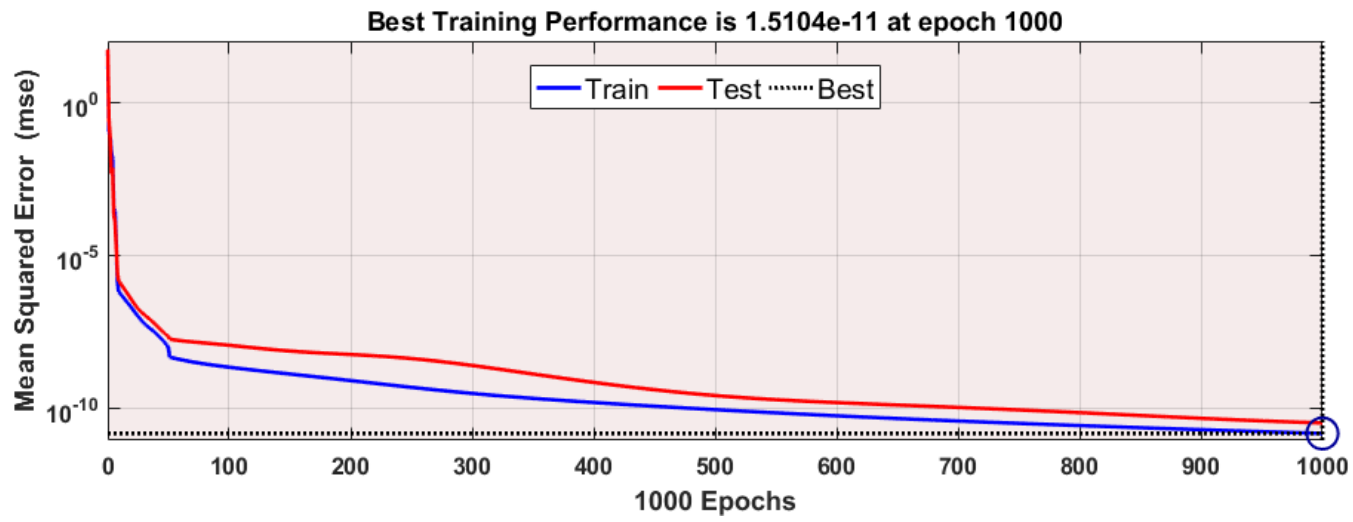

Best Training Performance is $3.0663 \mathrm{e}-12$ at epoch 1000

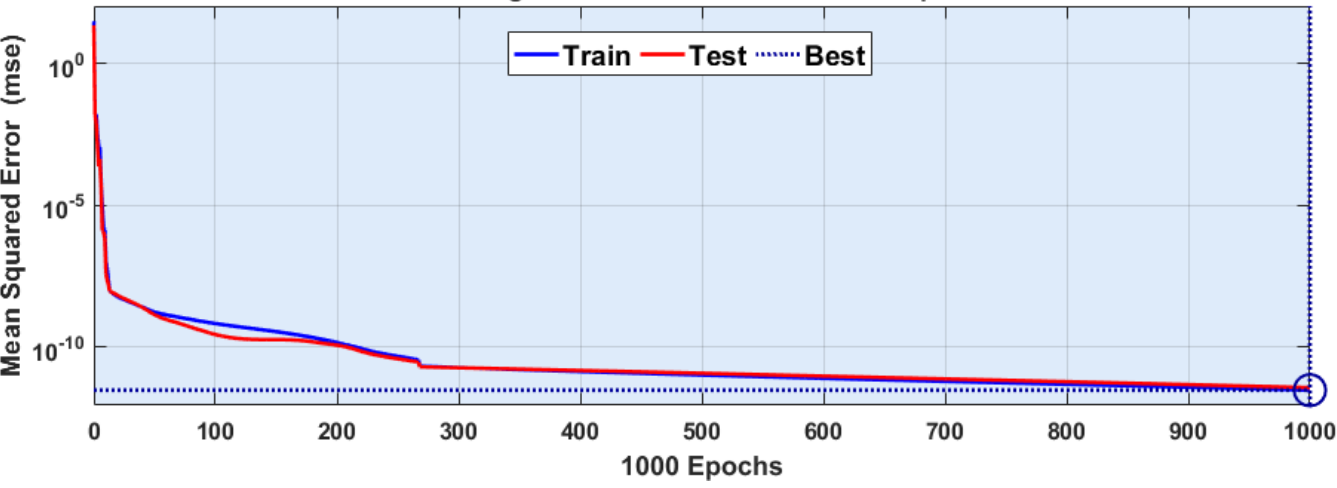

Best Training Performance is $1.7876 \mathrm{e}-10$ at epoch 1000

(c) Results for

IBNs-BR

convergence for

EES in Scenario 3

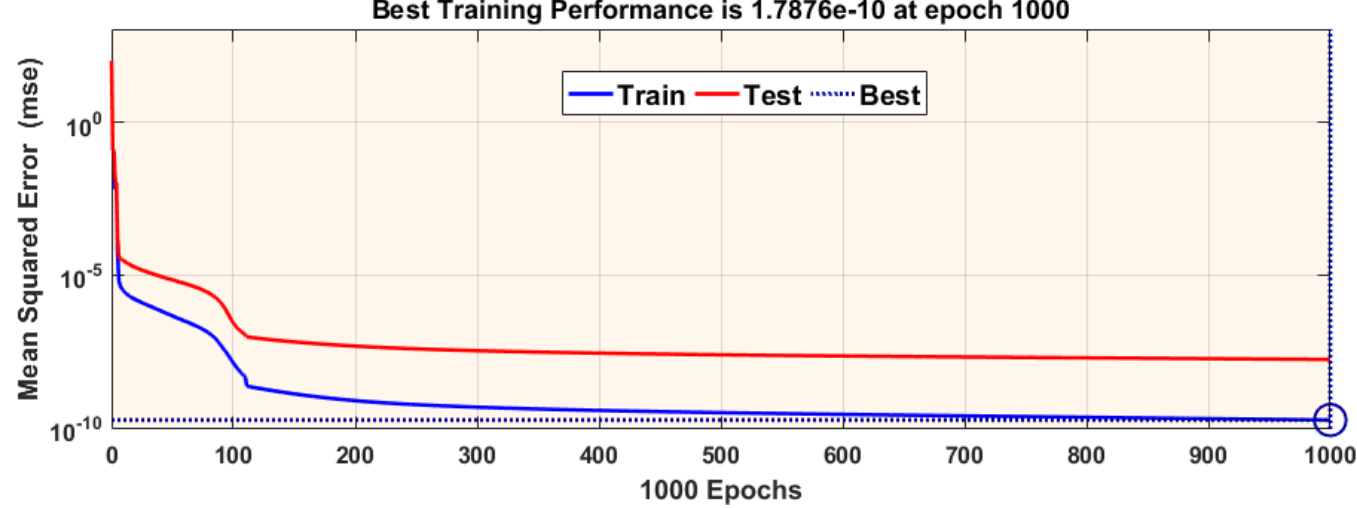

(d) Results for

IBNs-BR

convergence for

EES in Scenario 4

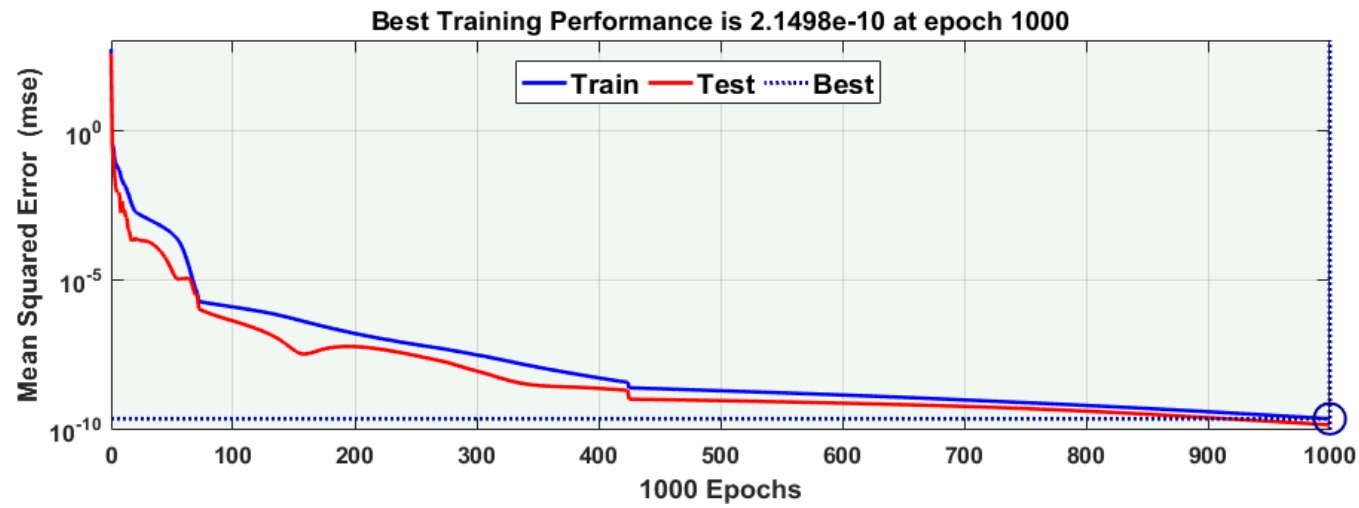

Figure 3. Convergence curves for MSE for solving variants of environmental economic system using proposed IBNs-BR. 


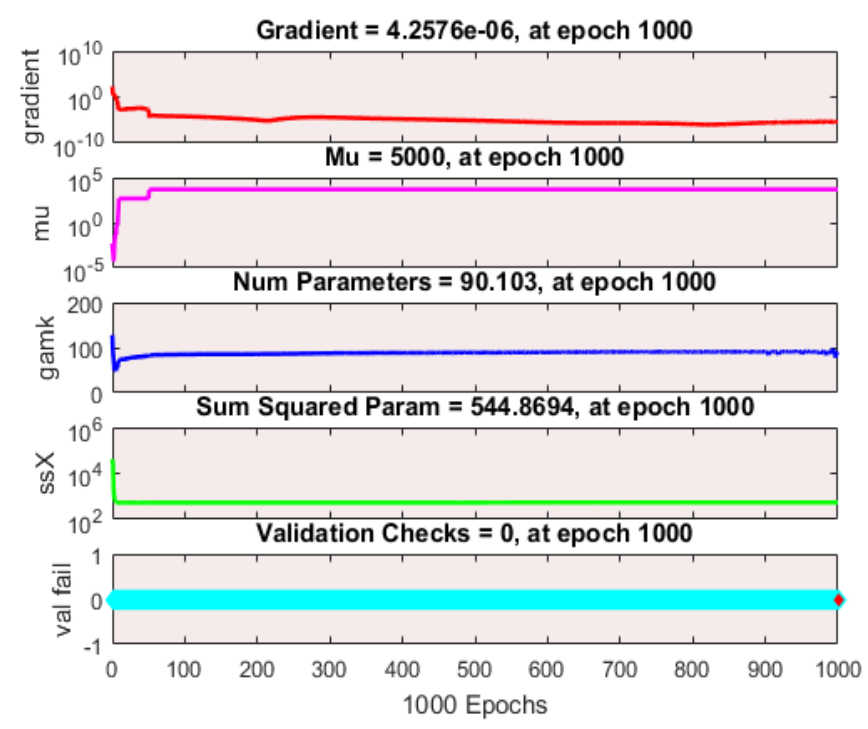

(a) Results of scenario 1 of EES Gradient $=2.8931 \mathrm{e}-07$, at epoch 1000
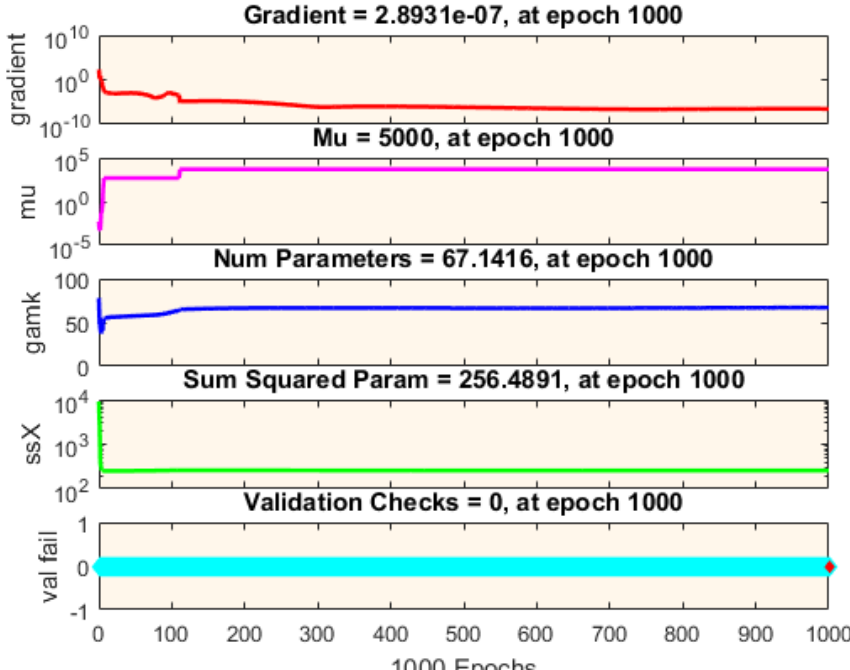

(c) Results of scenario 3 of EES

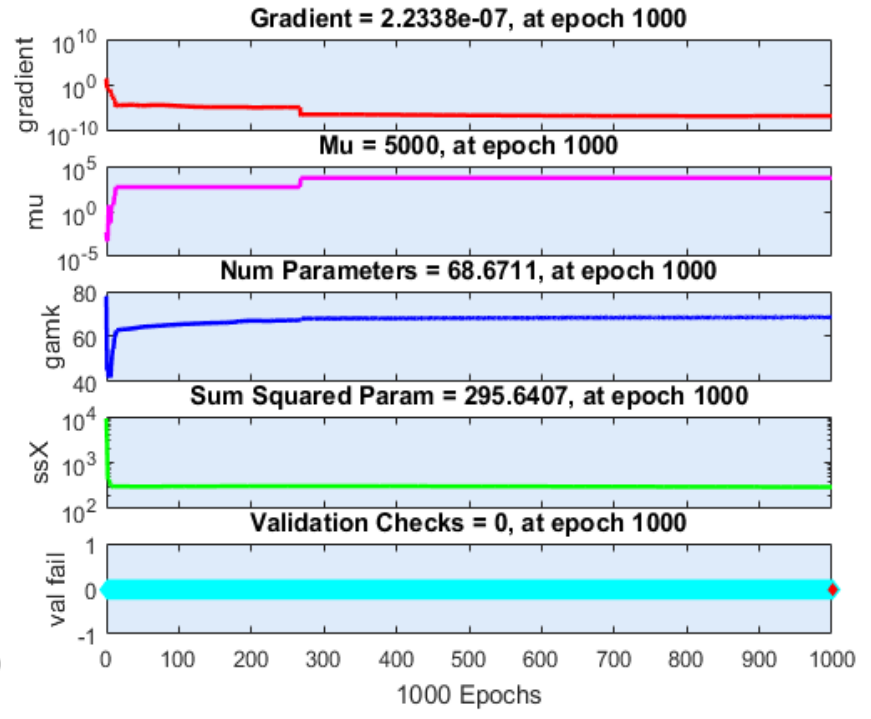

(b) Results of scenario 2 of EES
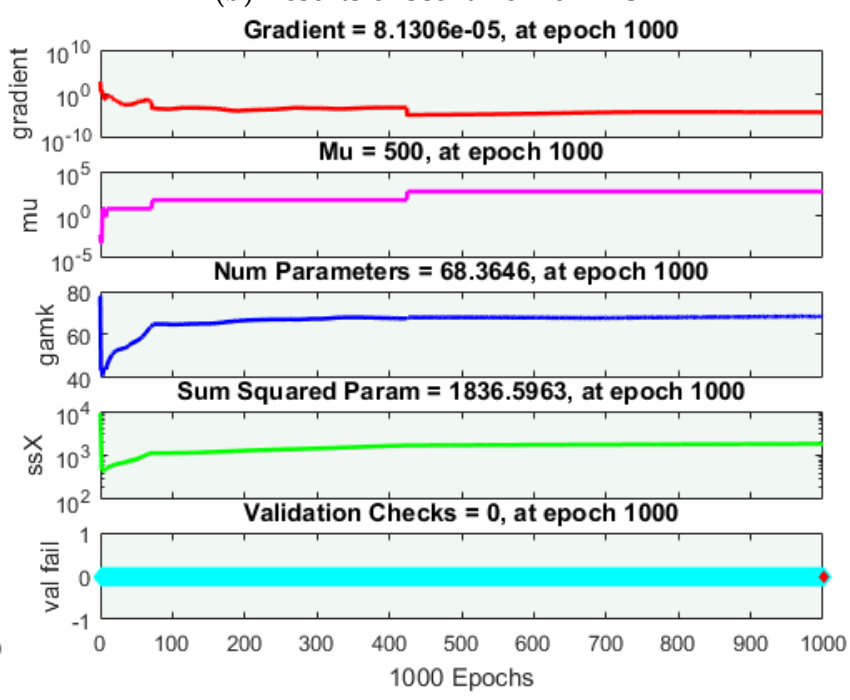

(d) Results of scenario 4 of EES

Figure 4. Backpropagation algorithm parameters for all four variants of environmental economic system. 

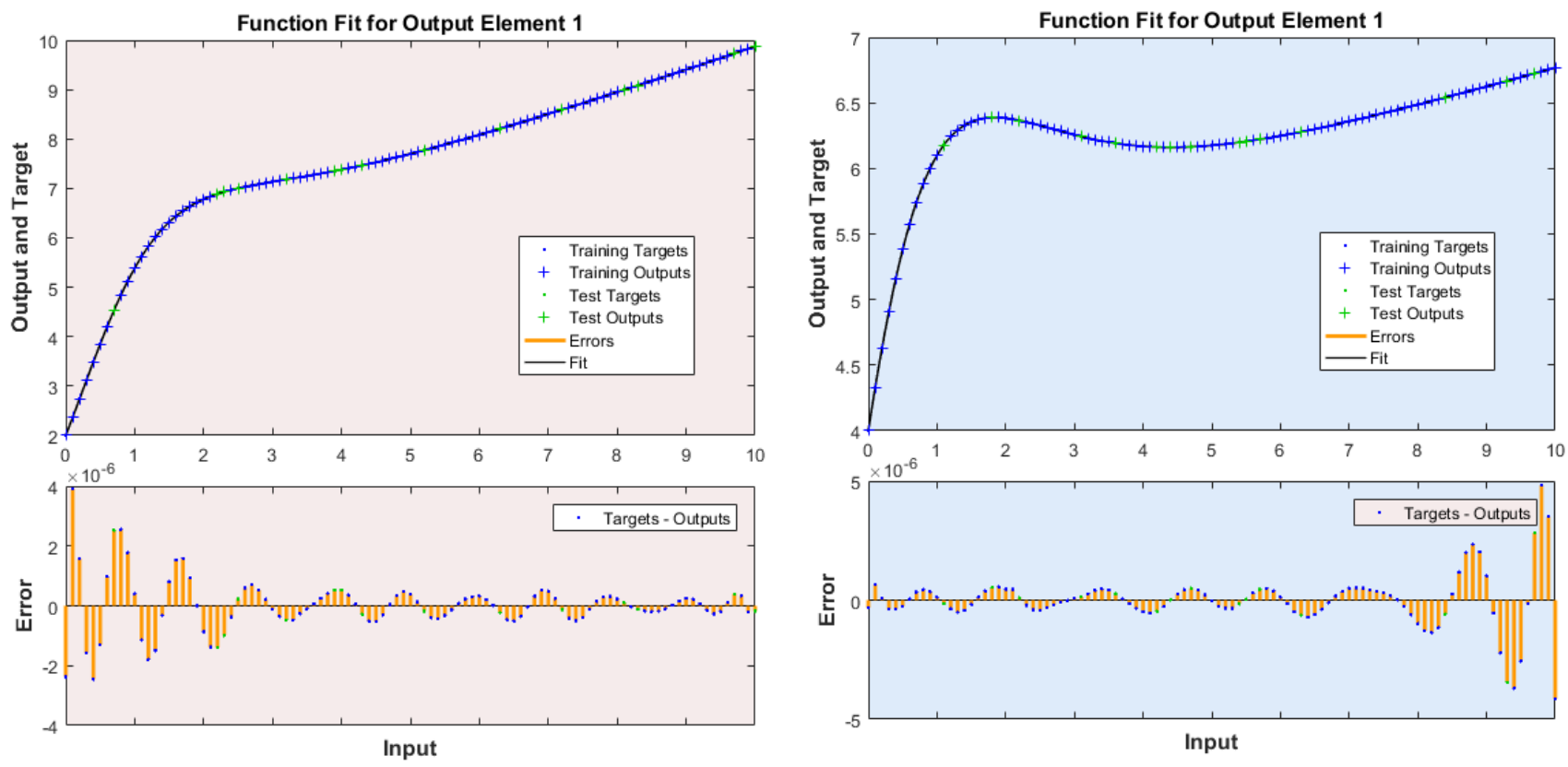

(a) Results for EES in Scenario 1

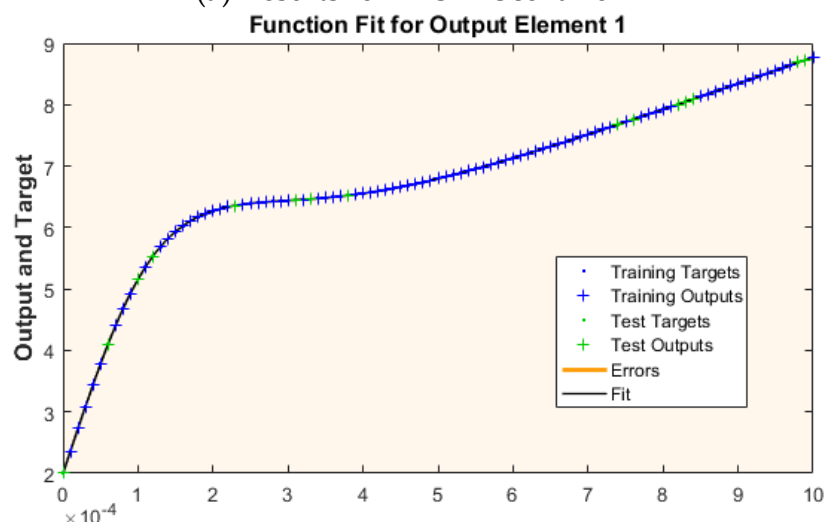

(b) Results for EES in Scenario 2
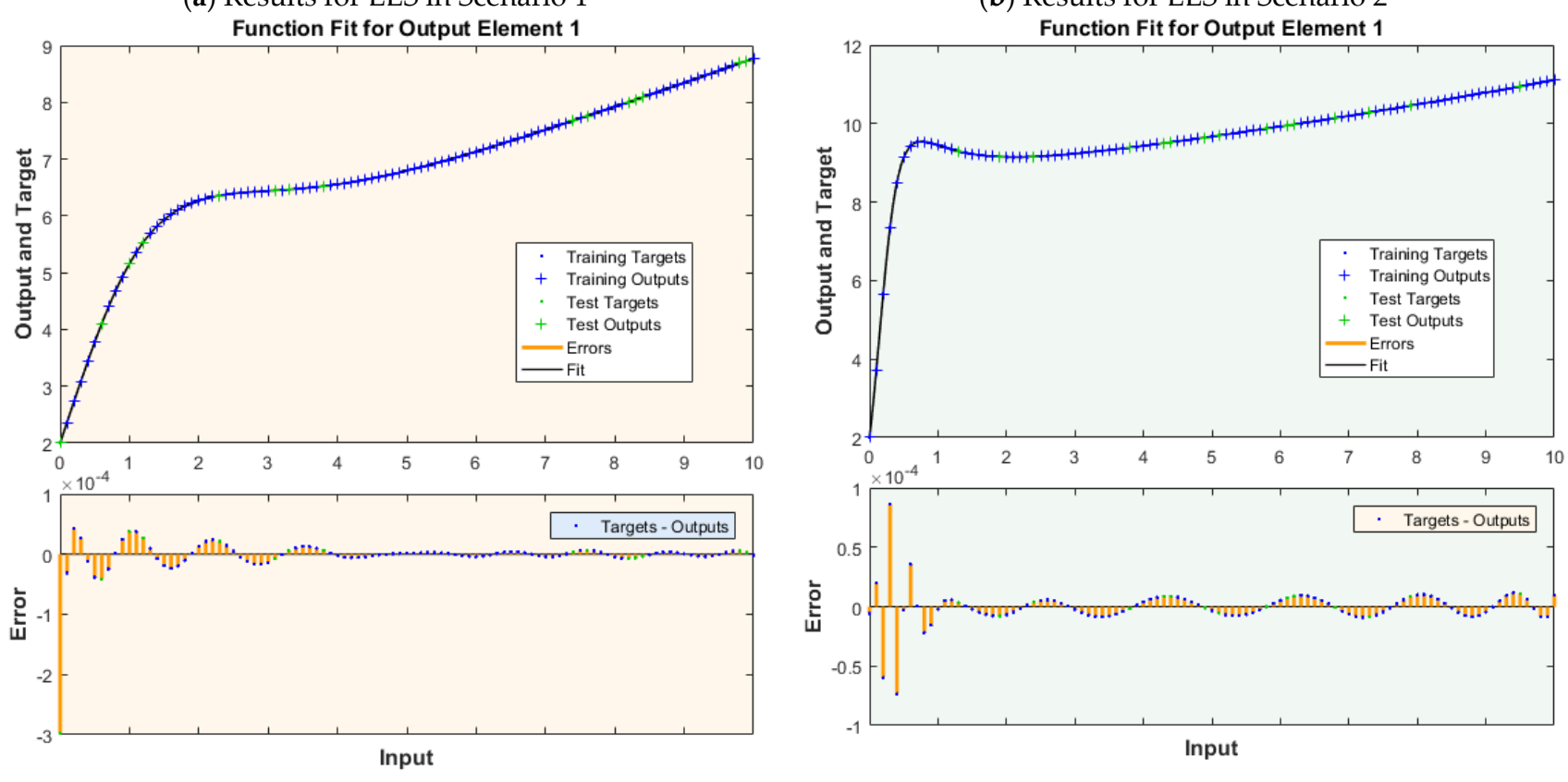

(c) Results for EES in Scenario 3

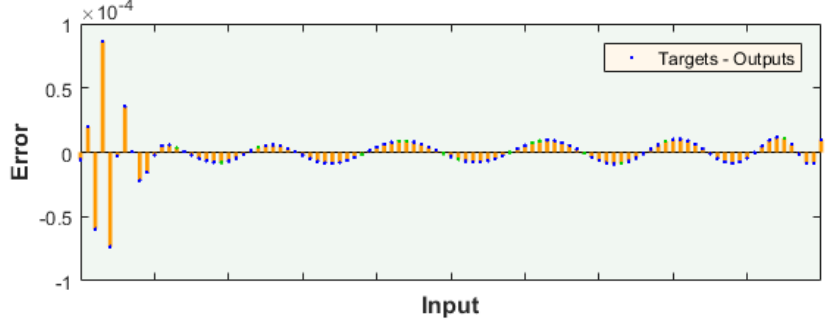

(d) Results for EES in Scenario 4

Figure 5. Comparison of proposed solutions of IBNs-BR from reference outcomes for all four variants of environmental economic system. 


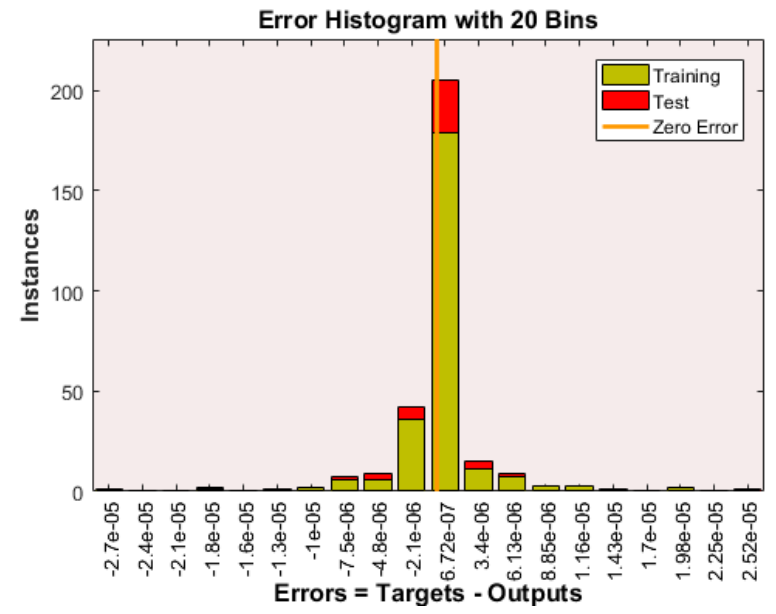

(a) Results for EES in Scenario 1

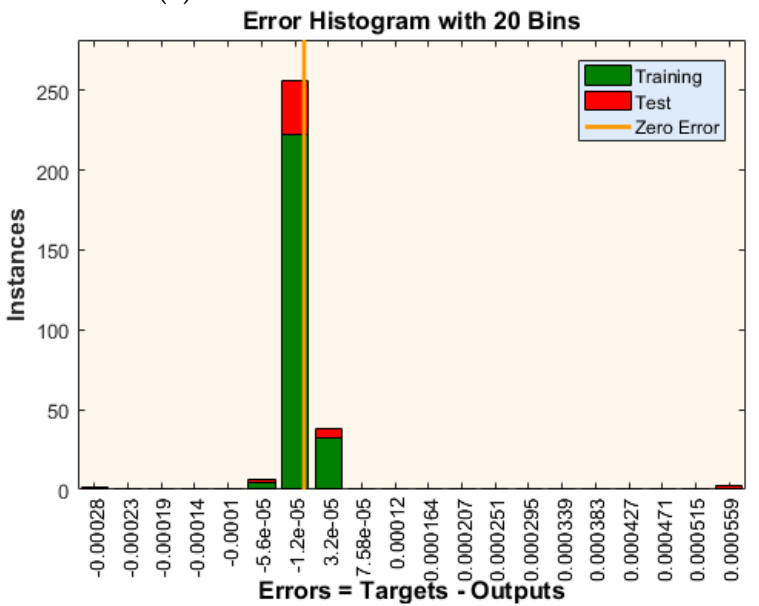

(c) Results for EES in Scenario 3

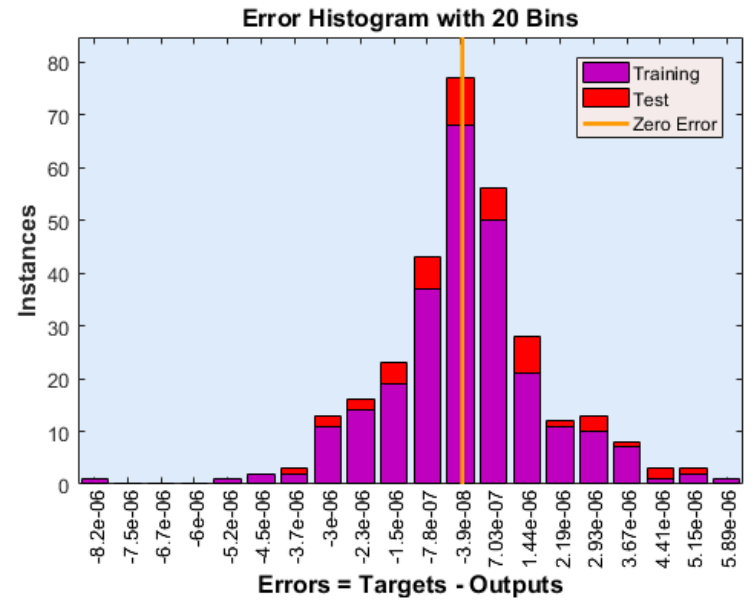

(b) Results for EES in Scenario 2

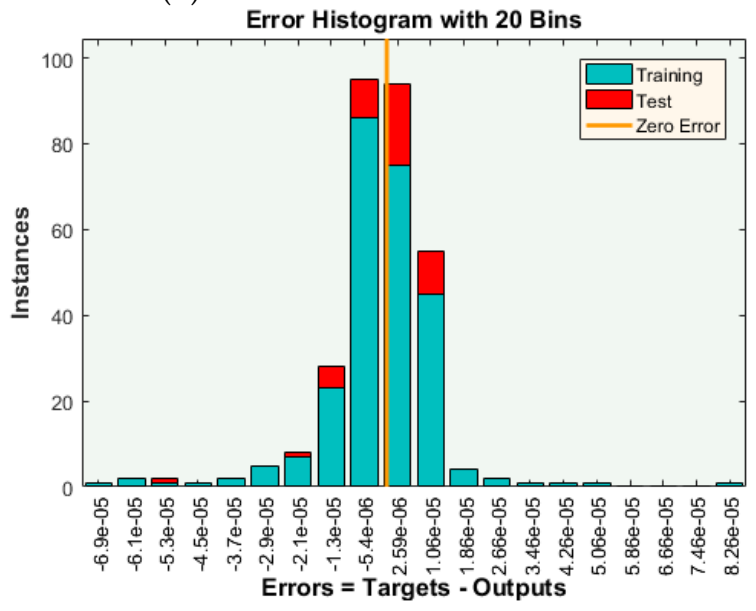

(a) Results for EES in Scenario 4

Figure 6. A tool of error histogram illustrations for comparative study of IBNs-BR for solving the environmental economic systems. 

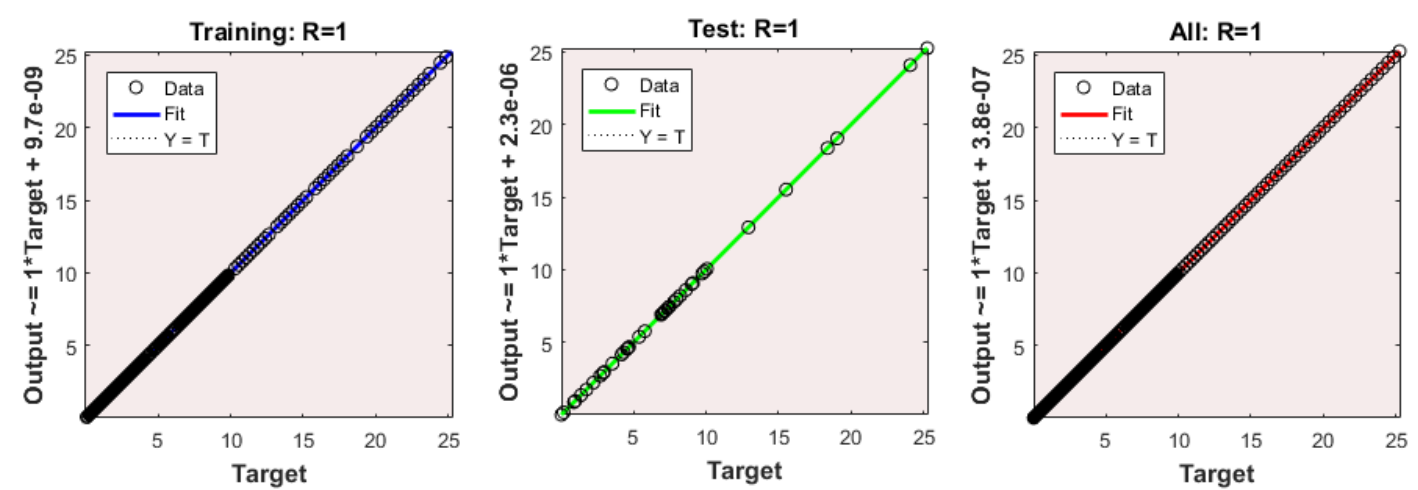

(a) Regression plots for EES in Scenario 1
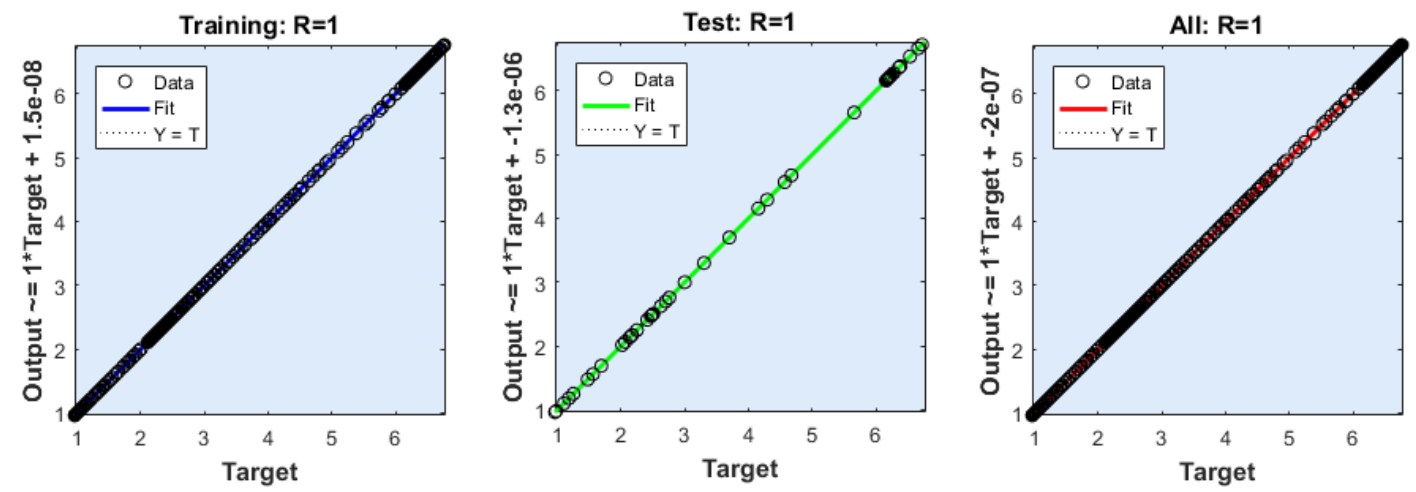

(b) Regression plots for EES in Scenario 2
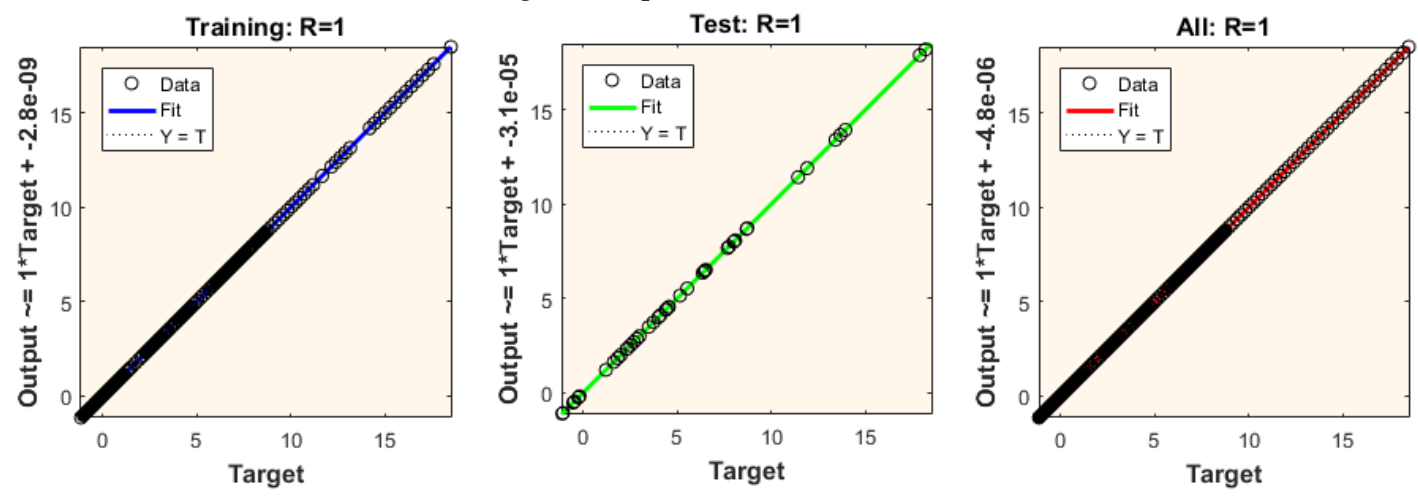

(c) Regression plots for EES in Scenario 3
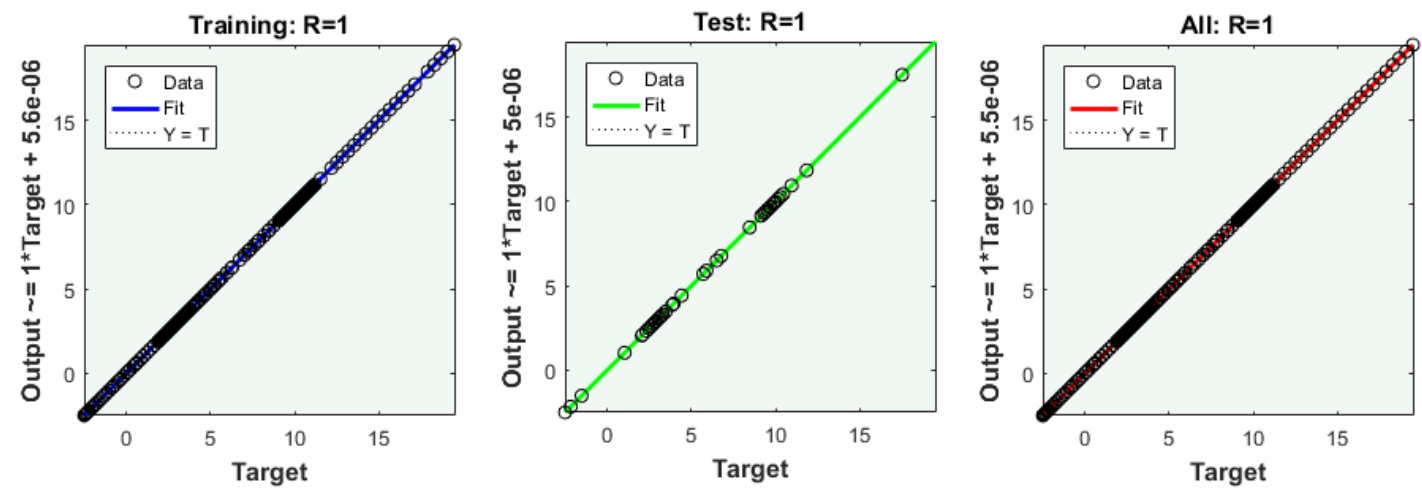

(d) Regression plots for EES in Scenario 4

Figure 7. Regression illustrations for comparative study of environmental economic systems. 


\subsection{Dynamical Analysis of EESs}

The collective behavior or dynamics of all four variants of EESs was also studied, and the results of the IBNs-RB are plotted in Figure 8 only with the reference numerical outcomes. The dynamics of EES differential models Equations (4)-(7) are portrayed in Figure $8 \mathrm{a}-\mathrm{d}$, respectively. Consistent matching/overlapping of the results of the proposed IBNs-RB and numerical solutions are seen for each case. In order to access the accuracy level, the values of absolute error are plotted in Figure 9 for each EES scenario. The values of absolute error lay around $10^{-8}$ to $10^{-4}, 10^{-8}$ to $10^{-5}, 10^{-8}$ to $10^{-4}$, and $10^{-8}$ to $10^{-4}$ for EESs in Equations (4)-(7), respectively, as portrayed in Figure 9a-d.

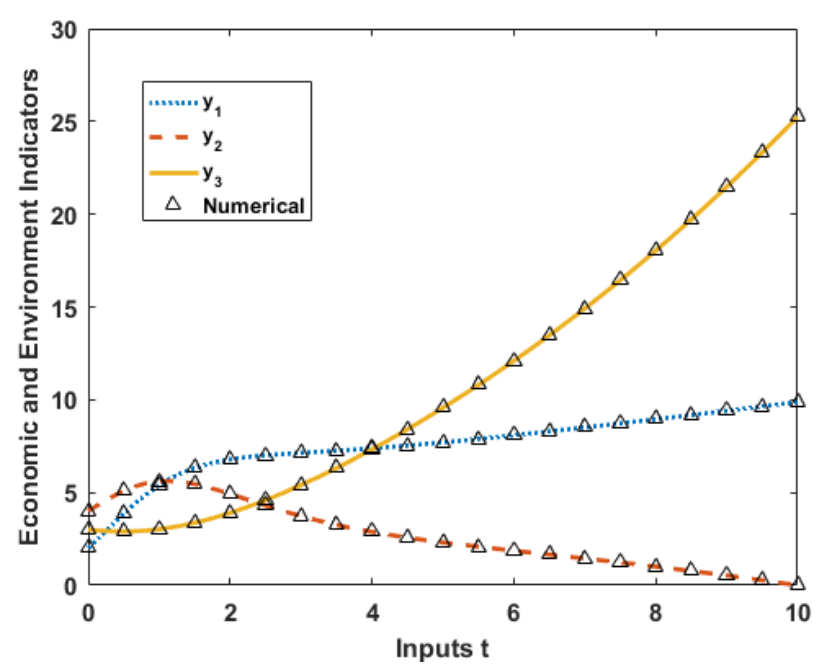

(a) Results for EES in Scenario 1

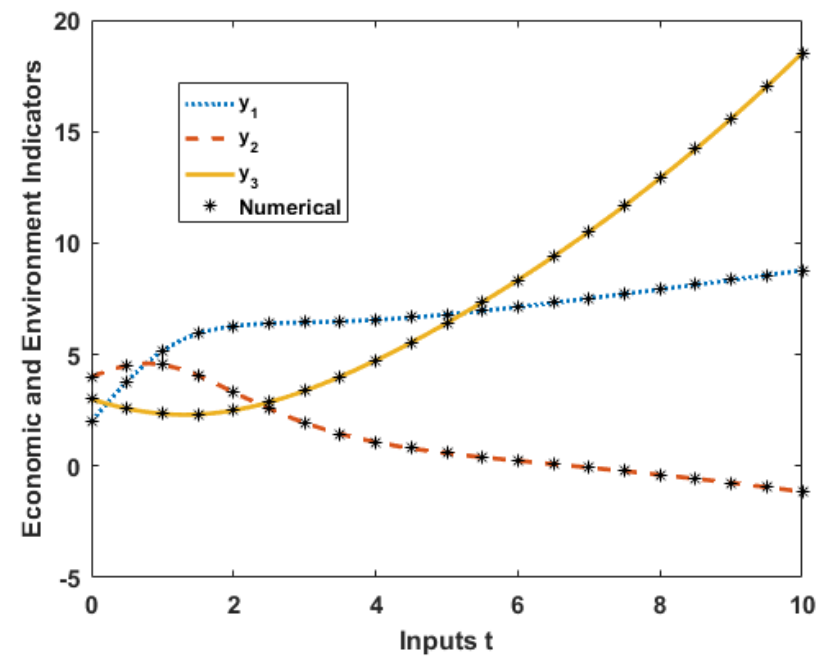

(c) Results for EES in Scenario 3

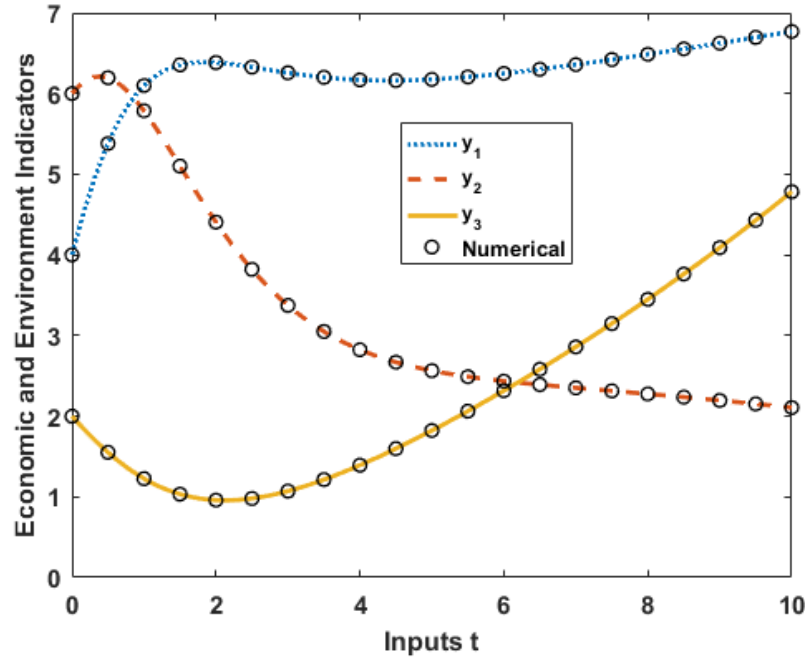

(b) Results for EES in Scenario 2

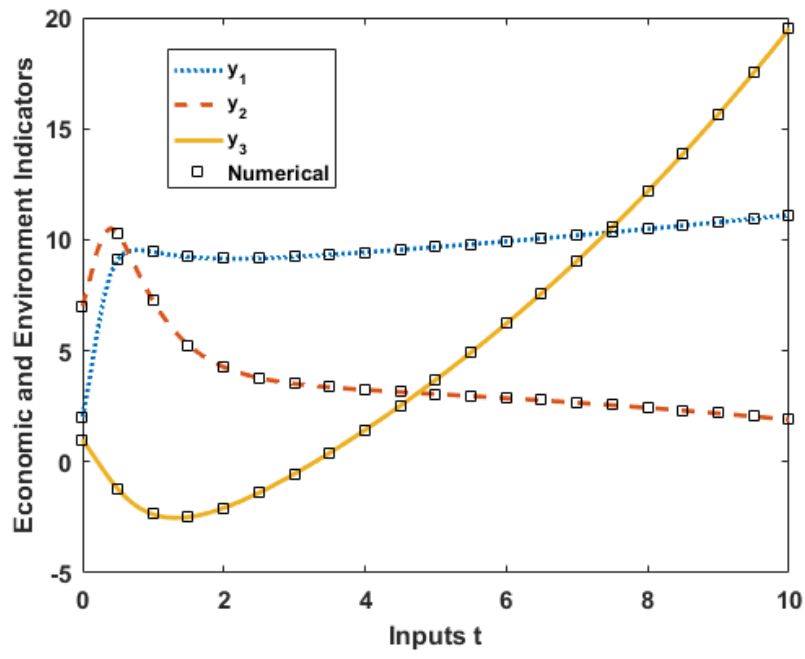

(d) Results for EES in Scenario 4

Figure 8. Dynamics of proposed solutions of IBNs-BR from reference numerical outcomes for all four variants of environmental economic system. 
(a) Results for EES in Scenario 1

(b) Results for EES in Scenario 2

(c) Results for EES in Scenario 3

(d) Results for EES in Scenario 4
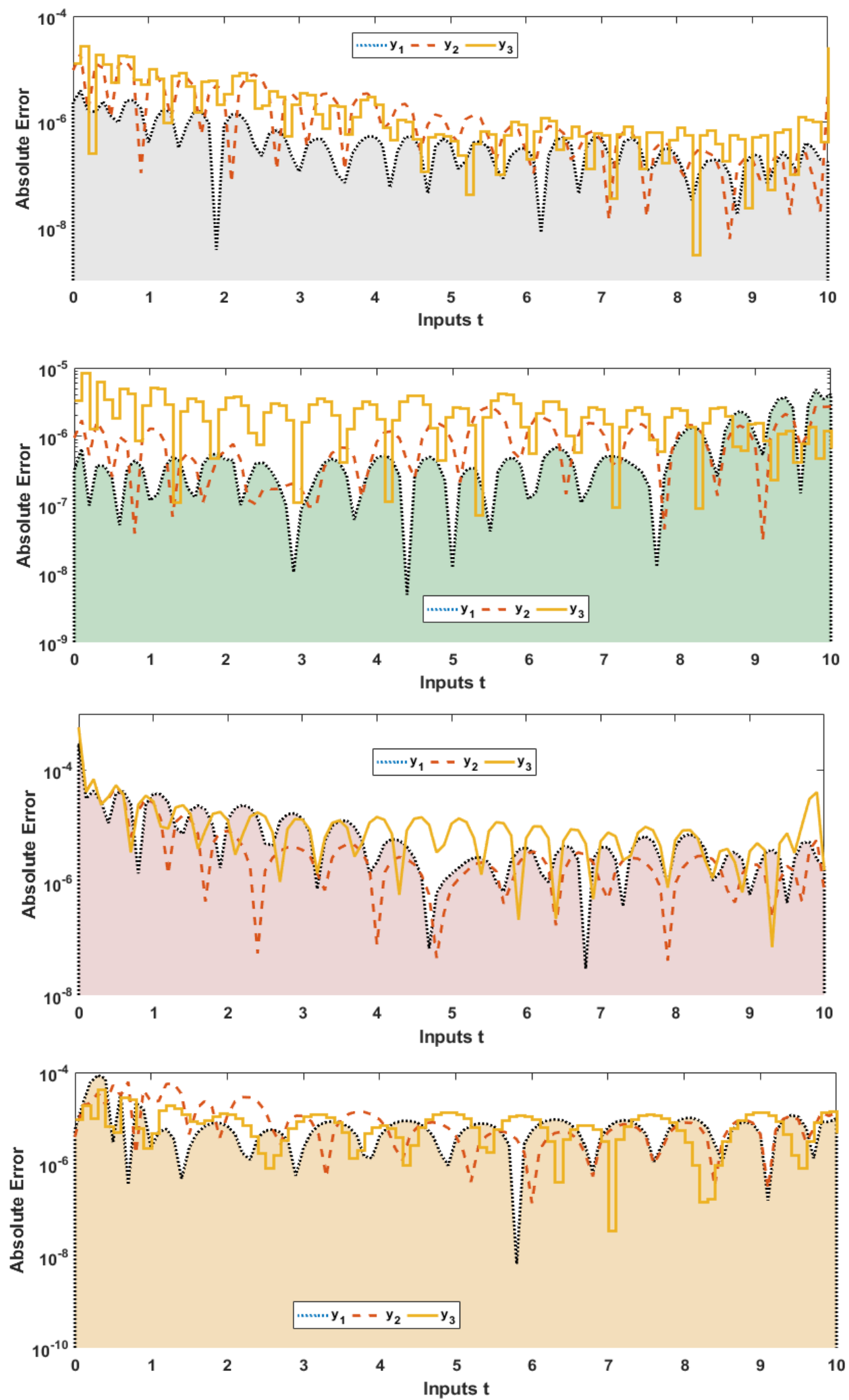

Figure 9. Comparison of AE for IBNs-BR from reference numerical outcomes for all four variants of environmental economic system.

\section{Conclusions}

The concluding remarks are summarized as follows: 
- The purpose of this study was the exploration of the artificial intelligence-based computing paradigm for the numerical treatment of mathematical models representing the environmental economic systems using the competency of intelligent backpropagation networks of Bayesian regularization.

- The governing relations of the system model were presented in the form of differential models to portray the dynamics of fundamental compartments or indicators for economic and environmental parameters.

- $\quad$ The reference datasets of EESs were assembled by the Adams numerical solver for different scenarios and were used effectively as inputs and targets of IBNs-BR to predict the approximate solutions for each scenario.

- The comparative studies based on convergence curves on the mean square error and absolute deviation from the reference results consistently verified the correctness of IBNs-BR for solving EESs with an accuracy of the order $10^{-5}$ to $10^{-8}$.

- The endorsement of results was further validated through performance evaluation by means of error histogram analyses and the regression index for each EES scenario.

- Besides the advantage of consistent precision, stability, and robustness, the limitation of IBNs-BR depended mainly on the availability of the quality dataset for nonlinear systems, which is normally restricted for particular tasks and originations.

In the future, the intelligent computing paradigm of IBNs-BR can be implemented to solve environmental pollution dynamics [54-57], production enterprise analysis [58,59], and financial models [60-62].

Author Contributions: Writing-original draft preparation, A.K.K., conceptualization, W.U.K. and Z.S.; methodology, M.A.Z.R.; software, M.A.Z.R.; validation, Y.H. and Z.S.; formal analysis, M.S.; resources, Y.H.; writing—review and editing, M.A.Z.R.; supervision, M.A.Z.R.; project administration, W.U.K.; funding acquisition, Y.H. All authors have read and agreed to the published version of the manuscript.

Funding: This work was supported by the National Natural Science Foundation of China under Grant Nos. 51977153, 51977161, and 51577046, the State Key Program of National Natural Science Foundation of China under Grant No. 51637004, the National Key Research and Development Plan "Important Scientific Instruments and Equipment Development" Grant No. 2016YFF0102200, the Equipment research project in advance Grant No. 41402040301, and the Wuhan Science and Technology Plan Project Grant No. 20201G01.

Institutional Review Board Statement: Not applicable.

Informed Consent Statement: Not applicable.

Data Availability Statement: Not applicable.

Conflicts of Interest: The authors declare no conflict of interest.

Appendix A. The Mathematical Formulation of the Adams Method Is Provided Here Consider the first-order representation of ODEs as:

$$
\frac{d y}{d t}=g(t, y), y(t)=y_{0}
$$

The ODEs system (3) is written as follows:

$$
\begin{aligned}
& y_{1_{0}}=C_{1}, y_{2_{0}}=C_{2}, y_{3_{0}}=C_{3}, \\
& y^{\prime}{ }_{1}=\frac{d y_{1}}{d t}, y_{2}^{\prime}=\frac{d y_{2}}{d t}, y^{\prime}{ }_{3}=\frac{d y_{3}}{d t} . \\
& y^{\prime}{ }_{1}=K_{1} y_{1}\left(5-y_{1}\right)+K_{2} y_{2}+K_{3} y_{3}, \\
& y^{\prime}{ }_{2}=K_{4} y_{1}\left(5-y_{1}\right)-K_{5} y_{2}\left(5-y_{2}\right)+K_{6} y_{3}, \\
& y^{\prime}{ }_{3}=K_{7} y_{1}-K_{8} y_{2} .
\end{aligned}
$$


Then, the Adams method operates in predictor-corrector steps; the predictor procedure for the two-step Adams-Bashforth expression is given for $y_{1}, y_{2}$, and $y_{3}$, respectively, as follows:

$$
\begin{aligned}
& \widetilde{y}_{1, n+1}=y_{1, n}+0.5 h\left(g\left(t_{n}, y_{1, n}\right)-g\left(t_{n-1}, y_{1, n-1}\right),\right. \\
& \widetilde{y}_{2, n+1}=y_{2, n}+0.5 h\left(g\left(t_{n}, y_{2, n}\right)-g\left(t_{n-1}, y_{2, n-1}\right),\right. \\
& \widetilde{y}_{3, n+1}=y_{3, n}+0.5 h\left(g\left(t_{n}, y_{3, n}\right)-g\left(t_{n-1}, y_{3, n-1}\right),\right.
\end{aligned}
$$

while the case of the four-step-based Adams-Bashforth expression for the predictor procedure is given as follows:

$$
\begin{aligned}
& \widetilde{y}_{1, n+1}=y_{1, n}+\frac{h}{24}\left(55 g\left(t_{n}, y_{1, n}\right)-59 g\left(t_{n-1}, y_{1, n-1}\right)+37 g\left(t_{n-2}, f_{1, n-2}\right)-9 g\left(t_{n-3}, f_{1, n-3}\right)\right), \\
& \widetilde{y}_{2, n+1}=y_{2, n}+\frac{h}{24}\left(55 g\left(t_{n}, y_{2, n}\right)-59 g\left(t_{n-1}, y_{2, n-1}\right)+37 g\left(t_{n-2}, f_{2, n-2}\right)-9 g\left(t_{n-3}, f_{2, n-3}\right)\right), \\
& \widetilde{y}_{3, n+1}=y_{3, n}+\frac{h}{24}\left(55 g\left(t_{n}, y_{3, n}\right)-59 g\left(t_{n-1}, y_{3, n-1}\right)+37 g\left(t_{n-2}, f_{3, n-2}\right)-9 g\left(t_{n-3}, f_{3, n-3}\right)\right),
\end{aligned}
$$

and similarly, the corrector procedure for the two and four-steps-based AdamsMoulton expression is given as follows:

$$
\begin{aligned}
& \widetilde{y}_{1, n+1}=y_{1, n}+0.5 h\left(g\left(t_{n}, \widetilde{y}_{1, n}\right)-g\left(t_{n-1}, y_{1, n-1}\right),\right. \\
& \widetilde{y}_{2, n+1}=y_{2, n}+0.5 h\left(g\left(t_{n}, \widetilde{y}_{2, n}\right)-g\left(t_{n-1}, y_{2, n-1}\right),\right. \\
& \widetilde{y}_{3, n+1}=y_{3, n}+0.5 h\left(g\left(t_{n}, \widetilde{y}_{3, n}\right)-g\left(t_{n-1}, y_{3, n-1}\right),\right.
\end{aligned}
$$

\begin{tabular}{|c|c|c|c|}
\hline \multirow{2}{*}{$\begin{array}{c}\text { Inputs } \\
t\end{array}$} & \multicolumn{3}{|c|}{ Economic Environment Indicators } \\
\hline & $y_{1}(t)$ & $y_{2}(t)$ & $y_{3}(t)$ \\
\hline 0 & 2 & 4 & 3 \\
\hline 0.5 & 3.84987346535515 & 5.08244212918718 & 2.89983206145214 \\
\hline 1.0 & 5.38531659314338 & 5.60035696874615 & 3.02244388419774 \\
\hline 1.5 & 6.31817116386359 & 5.45256756062941 & 3.36661141796232 \\
\hline 2.0 & 6.78228733954457 & 4.92388205874105 & 3.90153672089335 \\
\hline 2.5 & 7.00449663338051 & 4.30075644696836 & 4.59090339781144 \\
\hline 3.0 & 7.13623098005342 & 3.73058017059468 & 5.40443376949056 \\
\hline 3.5 & 7.25183335675313 & 3.25771668447669 & 6.32030055915814 \\
\hline 4.0 & 7.38077652717235 & 2.87767240448708 & 7.32412130274461 \\
\hline 4.5 & 7.53094834169699 & 2.56932561549838 & 8.40715686297488 \\
\hline 5.0 & 7.70123930149309 & 2.30972437108622 & 9.56461936718528 \\
\hline 5.5 & 7.88768461971776 & 2.07962841891784 & 10.7943453899990 \\
\hline 6.0 & 8.08617911929294 & 1.86475006148766 & 12.0958525223690 \\
\hline 6.5 & 8.29344995816018 & 1.65522848140345 & 13.4697126068641 \\
\hline 7.0 & 8.50721003291470 & 1.44456800915997 & 14.9171555129752 \\
\hline 7.5 & 8.72599101627560 & 1.22859562054423 & 16.4398277156209 \\
\hline 8.0 & 8.94890545811000 & 1.00463900609771 & 18.0396486908658 \\
\hline 8.5 & 9.17544072696511 & 0.770951089310535 & 19.7187265507377 \\
\hline 9.0 & 9.40531139975185 & 0.526336950522214 & 21.4793085598252 \\
\hline 9.5 & 9.63836456840631 & 0.269924665643338 & 23.3237522313186 \\
\hline 10.0 & 9.87452295609776 & 0.00102870600650036 & 25.2545082708319 \\
\hline
\end{tabular}

$$
\begin{aligned}
& \widetilde{y}_{1, n+1}=y_{1, n}+\frac{h}{24}\left(9 g\left(t_{n+1}, \widetilde{y}_{1, n+1}\right)+19 g\left(t_{n}, y_{1, n}\right)-5 g\left(t_{n-1}, y_{1, n-1}\right)+g\left(t_{n-2}, y_{1, n-2}\right)\right), \\
& \widetilde{y}_{2, n+1}=y_{2, n}+\frac{h}{24}\left(9 g\left(t_{n+1}, \widetilde{y}_{2, n+1}\right)+19 g\left(t_{n}, y_{2, n}\right)-5 g\left(t_{n-1}, y_{2, n-1}\right)+g\left(t_{n-2}, y_{2, n-2}\right)\right), \\
& \widetilde{y}_{3, n+1}=y_{3, n}+\frac{h}{24}\left(9 g\left(t_{n+1}, \widetilde{y}_{3, n+1}\right)+19 g\left(t_{n}, y_{3, n}\right)-5 g\left(t_{n-1}, y_{3, n-1}\right)+g\left(t_{n-2}, y_{3, n-2}\right)\right),
\end{aligned}
$$

Accordingly, one can formulate the Adams procedure for different numbers of steps.

\section{Appendix B. Outcomes of the Adams Methods for Creation of Dataset for IBNs-BR}

Table A1. Reference dataset for the environmental economic systems for scenario 1. 
Table A2. Reference dataset for the environmental economic systems for scenario 2.

\begin{tabular}{cccc}
\hline Inputs & \multicolumn{3}{c}{ Economic Environmental Indicators } \\
\hline$t$ & $\boldsymbol{y}_{\mathbf{1}}(\boldsymbol{t})$ & $\mathbf{y}_{\mathbf{2}}(\boldsymbol{t})$ & $\boldsymbol{y}_{\mathbf{3}}(\boldsymbol{t})$ \\
\hline 0 & 4 & 6 & 2 \\
\hline 0.5 & 5.38100474030686 & 6.19554526232834 & 1.55111733320595 \\
\hline 1.0 & 6.09927738409611 & 5.78633303573584 & 1.22577522357539 \\
\hline 1.5 & 6.35548747400663 & 5.10069533413258 & 1.03331636004833 \\
\hline 2.0 & 6.38365001669932 & 4.40540907962059 & 0.959395280990677 \\
\hline 2.5 & 6.32741059555454 & 3.82051677909423 & 0.980021495694433 \\
\hline 3.0 & 6.25670325749930 & 3.37310181214434 & 1.07134703343056 \\
\hline 3.5 & 6.20078445218686 & 3.04961767687740 & 1.21373076020701 \\
\hline 4.0 & 6.16905449643891 & 2.82392687172957 & 1.39254542281714 \\
\hline 4.5 & 6.16183411641528 & 2.66950845315801 & 1.59762820134015 \\
\hline 5.0 & 6.17572236173912 & 2.56393448235614 & 1.82233095710680 \\
\hline 5.5 & 6.20625079853538 & 2.48993218909104 & 2.06257614455027 \\
\hline 6.0 & 6.24915773972639 & 2.43503538904165 & 2.31606448168829 \\
\hline 6.5 & 6.30092288055574 & 2.39072629889620 & 2.58166694972839 \\
\hline 7.0 & 6.35890001042641 & 2.35148084367527 & 2.85898768612483 \\
\hline 7.5 & 6.42124445300171 & 2.31390273648284 & 3.14806654367728 \\
\hline 8.0 & 6.48675501340949 & 2.27602030458287 & 3.44918746382301 \\
\hline 8.5 & 6.55470105666067 & 2.23676036819480 & 3.76276202864773 \\
\hline 9.0 & 6.62467063891569 & 2.19558095066128 & 4.08926323486825 \\
\hline 9.5 & 6.69645295396079 & 2.15223108486534 & 4.42919091212818 \\
\hline 10.0 & 6.76995546919117 & 2.10660368730861 & 4.78305573981986 \\
\hline & & &
\end{tabular}

Table A3. Reference dataset for the environmental economic systems for scenario 3.

\begin{tabular}{cccc}
\hline Inputs. & \multicolumn{3}{c}{ Economic Environment Indicators } \\
\hline $\boldsymbol{T}$ & $\boldsymbol{y}_{\mathbf{1}}(\boldsymbol{t})$ & $\boldsymbol{y}_{\mathbf{2}}(\boldsymbol{t})$ & $\boldsymbol{y}_{\mathbf{3}}(\boldsymbol{t})$ \\
\hline 0 & 2 & 4 & 3 \\
\hline 0.5 & 3.77895369496549 & 4.50702615902379 & 2.57986824244645 \\
\hline 1.0 & 5.15606353978099 & 4.54004425328471 & 2.34284450318794 \\
\hline 1.5 & 5.93261912711357 & 4.05208819440336 & 2.31546105246105 \\
\hline 2.0 & 6.27163900644184 & 3.31411029940714 & 2.49639713634012 \\
\hline 2.5 & 6.39293747877504 & 2.57125227854606 & 2.86058165484202 \\
\hline 3.0 & 6.44010758236978 & 1.93983291656762 & 3.37456519454619 \\
\hline 3.5 & 6.48482877747975 & 1.44592884640699 & 4.00737246907302 \\
\hline 4.0 & 6.55602144687651 & 1.07367395867702 & 4.73486421256424 \\
\hline 4.5 & 6.66072938991790 & 0.793625447173174 & 5.54025511333904 \\
\hline 5.0 & 6.79599374517557 & 0.576092093208258 & 6.41301055044085 \\
\hline 5.5 & 6.95528465953494 & 0.396434840330269 & 7.34730733724330 \\
\hline 6.0 & 7.13183052675037 & 0.236411861902662 & 8.34058681384511 \\
\hline 6.5 & 7.32009801847897 & 0.0836561075986805 & 9.39240075126678 \\
\hline 7.0 & 7.51618092406137 & -0.0695999811947876 & 10.5035824842229 \\
\hline 7.5 & 7.71762412121082 & -0.227918622868782 & 11.6757031596123 \\
\hline 8.0 & 7.92304264364204 & -0.393841773143552 & 12.9107442606998 \\
\hline 8.5 & 8.13174176660711 & -0.568754881311778 & 14.2109166509352 \\
\hline 9.0 & 8.34342528591773 & -0.753444025495404 & 15.5785699425160 \\
\hline 9.5 & 8.558004638886684 & -0.948419108140589 & 17.0161524299301 \\
\hline 10.0 & 8.77548867529859 & -1.15408310298745 & 18.5261967960712 \\
\hline & & &
\end{tabular}


Table A4. Reference dataset for the environmental economic systems for scenario 4.

\begin{tabular}{cccc}
\hline Inputs & \multicolumn{3}{c}{ Economic Environment Indicators } \\
\hline $\boldsymbol{T}$ & $\boldsymbol{y}_{\mathbf{1}}(\boldsymbol{t})$ & $\boldsymbol{y}_{\mathbf{2}}(\boldsymbol{t})$ & $\boldsymbol{y}_{\mathbf{3}}(\boldsymbol{t})$ \\
\hline 0 & 2 & 7 & 1 \\
\hline 0.5 & 9.13011744363290 & 10.2815684832990 & -1.22670568611237 \\
\hline 1.0 & 9.45242179179267 & 7.23680780213549 & -2.36857214849340 \\
\hline 1.5 & 9.22579404439015 & 5.25387957522542 & -2.49057226245891 \\
\hline 2.0 & 9.14675405565877 & 4.26856757726780 & -2.07804071224031 \\
\hline 2.5 & 9.16482726545373 & 3.77685508340256 & -1.38871862767779 \\
\hline 3.0 & 9.23310909120640 & 3.51408824999788 & -0.542928109057926 \\
\hline 3.5 & 9.32676271704346 & 3.35431273982965 & 0.405194804976283 \\
\hline 4.0 & 9.43394815294133 & 3.23918943201718 & 1.43229103663283 \\
\hline 4.5 & 9.54927152237131 & 3.14192356772089 & 2.52916646815619 \\
\hline 5.0 & 9.67032894046072 & 3.05016712301859 & 3.69315485166567 \\
\hline 5.5 & 9.79606431199662 & 2.95814742297101 & 4.92463297490176 \\
\hline 6.0 & 9.92602277894565 & 2.86308318515682 & 6.22543190531976 \\
\hline 6.5 & 10.0600172804611 & 2.76355602213811 & 7.59811147878160 \\
\hline 7.0 & 10.1979802045286 & 2.65876881759113 & 9.04562878157438 \\
\hline 7.5 & 10.3398972698181 & 2.54820591356171 & 10.5711866022534 \\
\hline 8.0 & 10.4857783793664 & 2.43147767608113 & 12.1781652574761 \\
\hline 8.5 & 10.6356441136913 & 2.30824774138989 & 13.8700926865631 \\
\hline 9.0 & 10.7895202104004 & 2.17819978311887 & 15.6506325243711 \\
\hline 9.5 & 10.9474347210994 & 2.04102137937621 & 17.5235803589099 \\
\hline 10.0 & 11.1094171776640 & 1.89639672694744 & 19.4928646374896 \\
\hline & & &
\end{tabular}

\section{References}

1. Verma, M.; Verma, A.K.; Misra, A.K. Mathematical modeling and optimal control of carbon dioxide emissions from energy sector. Environ. Dev. Sustain. 2021, 1-26. [CrossRef]

2. Bherwani, H.; Anjum, S.; Gupta, A.; Singh, A.; Kumar, R. Establishing influence of morphological aspects on microclimatic conditions through GIS-assisted mathematical modeling and field observations. Environ. Dev. Sustain. 2021. [CrossRef]

3. Nasrollahi, Z.; Hashemi, M.S.; Bameri, S.; Taghvaee, V.M. Environmental pollution, economic growth, population, industrialization, and technology in weak and strong sustainability: Using STIRPAT model. Environ. Dev. Sustain. 2020, 22, 1105-1122. [CrossRef]

4. Montoya, O.Q.; Niño-Ruiz, E.D.; Pinel, N. On the mathematical modelling and data assimilation for air pollution assessment in the Tropical Andes. Environ. Sci. Pollut. Res. 2020, 27, 35993-36012. [CrossRef]

5. El Aferni, A.; Guettari, M.; Tajouri, T. Mathematical model of Boltzmann's sigmoidal equation applicable to the spreading of the coronavirus (Covid-19) waves. Environ. Sci. Pollut. Res. 2020,1-9. [CrossRef]

6. Hu, Y.; Jiang, H.; Zhong, Z. Impact of green credit on industrial structure in China: Theoretical mechanism and empirical analysis. Environ. Sci. Pollut. Res. 2020, 27, 10506-10519. [CrossRef] [PubMed]

7. $\mathrm{Wu}, \mathrm{Z}$.; $\mathrm{Wu}, \mathrm{W}$. Theoretical analysis of pollutant mixing zone considering lateral distribution of flow velocity and diffusion coefficient. Environ. Sci. Pollut. Res. 2018, 26, 30675-30683. [CrossRef] [PubMed]

8. Campos, C.F.; Cunha, M.C.; Santos, V.S.V.; de Campos Júnior, E.O.; Bonetti, A.M.; Pereira, B.B. Analysis of genotoxic effects on plants exposed to high traffic volume in urban crossing intersections. Chemosphere 2020, 259, 127511. [CrossRef] [PubMed]

9. Taylor, K.H. Resuscitating (and Refusing) Cartesian representations of daily life: When mobile and grid epistemologies of the city meet. Cogn. Instr. 2020, 38, 407-426. [CrossRef]

10. Chakraborty, A.; Maity, S.; Jain, S.; Mondal, S.P.; Alam, S. Hexagonal fuzzy number and its distinctive representation, ranking, defuzzification technique and application in production inventory management problem. Granul. Comput. 2021, 6, 507-521. [CrossRef]

11. Reyniers, D.J. Supplier-customer interaction in quality control. Ann. Oper. Res. 1992, 34, 307-330. [CrossRef]

12. Oliinyk, A.; Feshanych, L. The use of the apparatus of ordinary differential equations in simulation of economic and environmental systems. In Proceedings of the International Scientific and Technical Conference Information Technologies in Metallurgy and Machine Building; Ministry of Education and Science of Ukraine The National Metallurgical Academy of Ukraine, Dnipro, Ukraine, 17-19 March 2020; pp. 216-220. [CrossRef]

13. Di Vaio, A.; Palladino, R.; Hassan, R.; Escobar, O. Artificial intelligence and business models in the sustainable development goals perspective: A systematic literature review. J. Bus. Res. 2020, 121, 283-314. [CrossRef] 
14. Zhao, L.; Dai, T.; Qiao, Z.; Sun, P.; Hao, J.; Yang, Y. Application of artificial intelligence to wastewater treatment: A bibliometric analysis and systematic review of technology, economy, management, and wastewater reuse. Process. Saf. Environ. Prot. 2020, 133, 169-182. [CrossRef]

15. Di Vaio, A.; Boccia, F.; Landriani, L.; Palladino, R. Artificial intelligence in the agri-food system: Rethinking sustainable business models in the COVID-19 scenario. Sustainability 2020, 12, 4851. [CrossRef]

16. Gregurec, I.; Tomičić Furjan, M.; Tomičić-Pupek, K. The impact of COVID-19 on sustainable business models in SMEs. Sustainability 2021, 13, 1098. [CrossRef]

17. Kang, J.; Lee, H.J.; Jeong, S.H.; Lee, H.S.; Oh, K.J. Developing a Forecasting Model for Real Estate Auction Prices Using Artificial Intelligence. Sustainability 2020, 12, 2899. [CrossRef]

18. Kachba, Y.; Chiroli, D.M.D.G.; Belotti, J.T.; Alves, T.A.; Tadano, Y.D.S.; Siqueira, H. Artificial Neural Networks to Estimate the Influence of Vehicular Emission Variables on Morbidity and Mortality in the Largest Metropolis in South America. Sustainability 2020, 12, 2621. [CrossRef]

19. Ali, W.; Khan, W.U.; Raja, M.A.Z.; He, Y.; Li, Y. Design of Nonlinear Autoregressive Exogenous Model Based Intelligence Computing for Efficient State Estimation of Underwater Passive Target. Entropy 2021, 23, 550. [CrossRef]

20. Sabir, Z.; Raja, M.A.Z.; Guirao, J.L.; Shoaib, M. A novel design of fractional Meyer wavelet neural networks with application to the nonlinear singular fractional Lane-Emden systems. Alex. Eng. J. 2021, 60, 2641-2659. [CrossRef]

21. Sabir, Z.; Raja, M.A.Z.; Baleanu, D. Fractional Mayer Neuro-swarm heuristic solver for multi-fractional Order doubly singular model based on Lane-Emden equation. Fractals 2021, 29, 2140017. [CrossRef]

22. Sabir, Z.; Raja, M.A.Z.; Umar, M.; Shoaib, M. Design of neuro-swarming-based heuristics to solve the third-order nonlinear multi-singular Emden-Fowler equation. Eur. Phys. J. Plus 2020, 135, 410. [CrossRef]

23. Raja, M.A.Z.; Mehmood, J.; Sabir, Z.; Nasab, A.K.; Manzar, M.A. Numerical solution of doubly singular nonlinear systems using neural networks-based integrated intelligent computing. Neural Comput. Appl. 2019, 31, 793-812. [CrossRef]

24. Sabir, Z.; Raja, M.A.Z.; Shoaib, M.; Aguilar, J.G. FMNEICS: Fractional Meyer neuro-evolution-based intelligent computing solver for doubly singular multi-fractional order Lane-Emden system. Comput. Appl. Math. 2020, 39, 1-18. [CrossRef]

25. Raja, M.A.Z.; Shah, F.H.; Alaidarous, E.S.; Syam, M.I. Design of bio-inspired heuristic technique integrated with interior-point algorithm to analyze the dynamics of heartbeat model. Appl. Soft Comput. 2017, 52, 605-629. [CrossRef]

26. Raja, M.A.Z.; Shah, F.H.; Syam, M.I. Intelligent computing approach to solve the nonlinear Van der Pol system for heartbeat model. Neural Comput. Appl. 2017, 30, 3651-3675. [CrossRef]

27. Umar, M.; Sabir, Z.; Raja, M.A.Z.; Amin, F.; Saeed, T.; Guerrero-Sanchez, Y. Integrated neuro-swarm heuristic with interior-point for nonlinear SITR model for dynamics of novel COVID-19. Alex. Eng. J. 2021, 60, 2811-2824. [CrossRef]

28. Umar, M.; Sabir, Z.; Raja, M.A.Z.; Shoaib, M.; Gupta, M.; Sánchez, Y.G. A Stochastic Intelligent Computing with Neuro-Evolution Heuristics for Nonlinear SITR System of Novel COVID-19 Dynamics. Symmetry 2020, 12, 1628. [CrossRef]

29. Umar, M.; Raja, M.A.Z.; Sabir, Z.; Alwabli, A.S.; Shoaib, M. A stochastic computational intelligent solver for numerical treatment of mosquito dispersal model in a heterogeneous environment. Eur. Phys. J. Plus 2020, 135, 1-23. [CrossRef]

30. Guo, Q.; He, Z. Prediction of the confirmed cases and deaths of global COVID-19 using artificial intelligence. Environ. Sci. Pollut. Res. 2021, 28, 11672-11682. [CrossRef]

31. Umar, M.; Sabir, Z.; Raja, M.A.Z. Intelligent computing for numerical treatment of nonlinear prey-predator models. Appl. Soft Comput. 2019, 80, 506-524. [CrossRef]

32. Raja, M.A.Z.; Malik, M.F.; Chang, C.L.; Shoaib, M.; Shu, C.M. Design of backpropagation networks for bioconvection model in transverse transportation of rheological fluid involving Lorentz force interaction and gyrotactic microorganisms. J. Taiwan Inst. Chem. Eng. 2021, 121, 276-291. [CrossRef]

33. Ilyas, H.; Ahmad, I.; Raja, M.A.Z.; Tahir, M.B.; Shoaib, M. Intelligent networks for crosswise stream nanofluidic model with $\mathrm{Cu}-\mathrm{H} 2 \mathrm{O}$ over porous stretching medium. Int. J. Hydrog. Energy 2021, 46, 15322-15336. [CrossRef]

34. Umar, M.; Sabir, Z.; Raja, M.A.Z.; Sánchez, Y.G. A stochastic numerical computing heuristic of SIR nonlinear model based on dengue fever. Results Phys. 2020, 19, 103585. [CrossRef]

35. Aljohani, J.L.; Alaidarous, E.S.; Raja, M.A.Z.; Shoaib, M.; Alhothuali, M.S. Intelligent computing through neural networks for numerical treatment of non-Newtonian wire coating analysis model. Sci. Rep. 2021, 11, 1-32.

36. Ara, A.; Khan, N.A.; Razzaq, O.A.; Hameed, T.; Raja, M.A.Z. Wavelets optimization method for evaluation of fractional partial differential equations: An application to financial modelling. Adv. Differ. Equ. 2018, 2018, 8. [CrossRef]

37. Bukhari, A.H.; Raja, M.A.Z.; Sulaiman, M.; Islam, S.; Shoaib, M.; Kumam, P. Fractional neuro-sequential ARFIMA-LSTM for financial market forecasting. IEEE Access 2020, 8, 71326-71338. [CrossRef]

38. Khan, B.S.; Raja, M.A.Z.; Qamar, A.; Chaudhary, N.I. Design of moth flame optimization heuristics for integrated power plant system containing stochastic wind. Appl. Soft Comput. 2021, 104, 107193. [CrossRef]

39. Khan, I.; Raja, M.A.Z.; Shoaib, M.; Kumam, P.; Alrabaiah, H.; Shah, Z.; Islam, S. Design of Neural Network with LevenbergMarquardt and Bayesian Regularization Backpropagation for Solving Pantograph Delay Differential Equations. IEEE Access 2020, 8, 137918-137933. [CrossRef]

40. Wali, A.S.; Tyagi, A. Comparative Study of Advance Smart Strain Approximation Method Using Levenberg-Marquardt and Bayesian Regularization Backpropagation Algorithm. Mater. Today Proc. 2020, 21, 1380-1395. [CrossRef]

41. Zhao, H.; Zhang, C. An online-learning-based evolutionary many-objective algorithm. Inf. Sci. 2020, 509, 1-21. [CrossRef] 
42. Ilyas, H.; Raja, M.A.Z.; Ahmad, I.; Shoaib, M. A novel design of Gaussian Wavelet Neural Networks for nonlinear Falkner-Skan systems in fluid dynamics. Chin. J. Phys. 2021, 72, 386-402. [CrossRef]

43. Dulebenets, M.A. A novel memetic algorithm with a deterministic parameter control for efficient berth scheduling at marine container terminals. Marit. Bus. Rev. 2017, 2, 302-330. [CrossRef]

44. Shoaib, M.; Raja, M.A.Z.; Khan, M.A.R.; Farhat, I.; Awan, S.E. Neuro-Computing Networks for Entropy Generation under the Influence of MHD and Thermal Radiation. Surf. Interfaces 2021, 25, 101243. [CrossRef]

45. Liu, Z.Z.; Wang, Y.; Huang, P.Q. AnD: A many-objective evolutionary algorithm with angle-based selection and shift-based density estimation. Inf. Sci. 2020, 509, 400-419. [CrossRef]

46. Pasha, J.; Dulebenets, M.A.; Kavoosi, M.; Abioye, O.F.; Wang, H.; Guo, W. An Optimization Model and Solution Algorithms for the Vehicle Routing Problem with a "Factory-in-a-Box". IEEE Access 2020, 8, 134743-134763. [CrossRef]

47. Sabir, Z.; Sabir, Z.; Raja, M.A.Z.; Le, D.-N.; Aly, A.A. A neuro-swarming intelligent heuristic for second-order nonlinear Lane-Emden multi-pantograph delay differential system. Complex. Intell. Syst. 2021. [CrossRef]

48. D'Angelo, G.; Pilla, R.; Tascini, C.; Rampone, S. A proposal for distinguishing between bacterial and viral meningitis using genetic programming and decision trees. Soft Comput. 2019, 23, 11775-11791. [CrossRef]

49. Naz, S.; Raja, M.A.Z.; Mehmood, A.; Zameer, A.; Shoaib, M. Neuro-intelligent networks for Bouc-Wen hysteresis model for piezostage actuator. Eur. Phys. J. Plus 2021, 136, 1-20. [CrossRef]

50. Panda, N.; Majhi, S.K. How effective is the salp swarm algorithm in data classification. In Computational Intelligence in Pattern Recognition; Springer: Singapore, 2020; pp. 579-588.

51. Mehmood, A.; Shi, P.; Raja, M.A.Z.; Zameer, A.; Chaudhary, N.I. Design of backtracking search heuristics for parameter estimation of power signals. Neural Comput. Appl. 2021, 33, 1479-1496. [CrossRef]

52. Awais, M.; Awan, S.E.; Raja, M.A.Z.; Shoaib, M. Effects of Gyro-Tactic organisms in bio-convective nano-material with heat immersion, stratification, and viscous dissipation. Arab. J. Sci. Eng. 2021, 46, 5907-5920. [CrossRef]

53. Awan, S.E.; Raja, M.A.Z.; Gul, F.; Khan, Z.A.; Mehmood, A.; Shoaib, M. Numerical Computing Paradigm for Investigation of Micropolar Nanofluid Flow between Parallel Plates System with Impact of Electrical MHD and Hall Current. Arab. J. Sci. Eng. 2021, 46, 645-662. [CrossRef]

54. Brodny, J.; Tutak, M. The analysis of similarities between the European Union countries in terms of the level and structure of the emissions of selected gases and air pollutants into the atmosphere. J. Clean. Prod. 2021, 279, 123641. [CrossRef]

55. Tutak, M.; Brodny, J.; Bindzár, P. Assessing the Level of Energy and Climate Sustainability in the European Union Countries in the Context of the European Green Deal Strategy and Agenda 2030. Energies 2021, 14, 1767. [CrossRef]

56. Tutak, M.; Brodny, J.; Szurgacz, D.; Sobik, L.; Zhironkin, S. The Impact of the Ventilation System on the Methane Release Hazard and Spontaneous Combustion of Coal in the Area of Exploitation-A Case Study. Energies 2020, 13, 4891. [CrossRef]

57. Brodny, J.; Tutak, M. The Use of Artificial Neural Networks to Analyze Greenhouse Gas and Air Pollutant Emissions from the Mining and Quarrying Sector in the European Union. Energies 2020, 13, 1925. [CrossRef]

58. Tutak, M.; Brodny, J.; Dobrowolska, M. Assessment of work conditions in a production enterprise-A case study. Sustainability 2020, 12, 5390. [CrossRef]

59. Tutak, M. The influence of the permeability of the fractures zone around the heading on the concentration and distribution of methane. Sustainability 2020, 12, 16. [CrossRef]

60. Nosratabadi, S.; Pinter, G.; Mosavi, A.; Semperger, S. Sustainable banking; Evaluation of the European business models. Sustainability 2020, 12, 2314. [CrossRef]

61. Rjoub, H.; Odugbesan, J.A.; Adebayo, T.S.; Wong, W.K. Sustainability of the moderating role of financial development in the determinants of environmental degradation: Evidence from Turkey. Sustainability 2021, 13, 1844. [CrossRef]

62. Nosratabadi, S.; Mosavi, A.; Shamshirband, S.; Kazimieras Zavadskas, E.; Rakotonirainy, A.; Chau, K.W. Sustainable business models: A review. Sustainability 2019, 11, 1663. [CrossRef] 